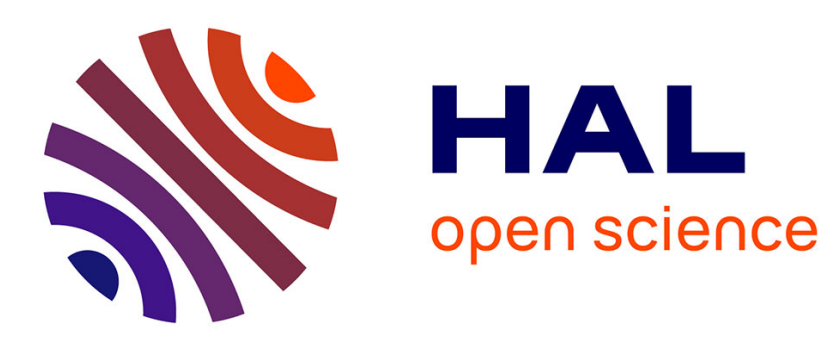

\title{
Functional breadth and home-field advantage generate functional differences among soil microbial decomposers
}

Nicolas Fanin, Nathalie Fromin, Isabelle Bertrand

\section{To cite this version:}

Nicolas Fanin, Nathalie Fromin, Isabelle Bertrand. Functional breadth and home-field advantage generate functional differences among soil microbial decomposers. Ecology, 2015, 97 (4), 10.1890/151263.1. hal-01269374

\author{
HAL Id: hal-01269374 \\ https://hal.science/hal-01269374
}

Submitted on 27 May 2020

HAL is a multi-disciplinary open access archive for the deposit and dissemination of scientific research documents, whether they are published or not. The documents may come from teaching and research institutions in France or abroad, or from public or private research centers.
L'archive ouverte pluridisciplinaire HAL, est destinée au dépôt et à la diffusion de documents scientifiques de niveau recherche, publiés ou non, émanant des établissements d'enseignement et de recherche français ou étrangers, des laboratoires publics ou privés. 


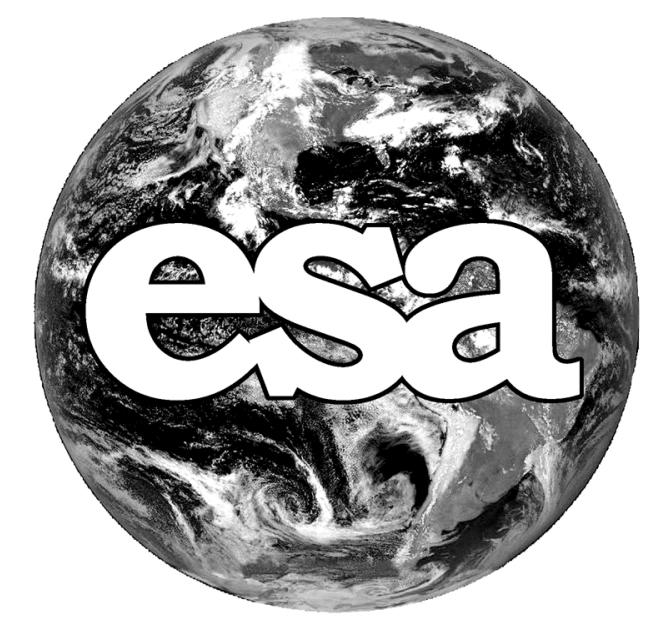

\section{ECOLOGICAL \\ SOCIETY \\ OF AMERICA}

Ecology/Ecological Monographs/Ecological Applications

\section{PREPRINT}

This preprint is a PDF of a manuscript that has been accepted for publication in an ESA journal. It is the final version that was uploaded and approved by the author(s). While the paper has been through the usual rigorous peer review process of ESA journals, it has not been copy-edited, nor have the graphics and tables been modified for final publication. Also note that the paper may refer to online Appendices and/or Supplements that are not yet available. We have posted this preliminary version of the manuscript online in the interest of making the scientific findings available for distribution and citation as quickly as possible following acceptance. However, readers should be aware that the final, published version will look different from this version and may also have some differences in content.

The doi for this manuscript and the correct format for citing the paper are given at the top of the online (html) abstract.

Once the final published version of this paper is posted online, it will replace the preliminary version at the specified doi. 
1 Title: Functional breadth and home-field advantage generate functional differences among soil

2 microbial decomposers

3

4 List of authors: Nicolas Fanin ${ }^{1,2}$, Nathalie Fromin ${ }^{3,4}$, Isabelle Bertrand ${ }^{1,5,6}$.

5

6 Postal addresses: ${ }^{1}$ INRA, UMR 614 Fractionnement des AgroRessources et Environnement, 2

7 esplanade Roland Garros, F-51100 Reims, France; ${ }^{2}$ Department of Forest Ecology and

8 Management, Swedish University of Agricultural Sciences, Umeå, Sweden, ${ }^{3}$ Centre d'Ecologie

9 Fonctionnelle et Evolutive (CEFE), CNRS - Université de Montpellier - Université Paul Valéry

10 Montpellier - EPHE, 1919 Route de Mende, F-34293 Montpellier Cedex 5, France, ${ }^{4}$ PROMES -

11 CNRS, 7 rue du Four Solaire, F66120 Odeillo, France, ${ }^{5}$ INRA, UMR Eco\&Sols, 2 Place Viala,

1234060 Montpellier Cedex 1, France, ${ }^{6}$ Corresponding author: Isabelle Bertrand,

13 isabelle.bertrand@supagro.inra.fr

14

15 E-mail addresses: nicolas.fanin@slu.se, nathalie.fromin@cefe.cnrs.fr,

16 isabelle.bertrand@supagro.inra.fr

17

18 Running title: Functional ability of soil microbes

19

20 Abstract. (350 words) In addition to the effect of litter quality (LQ) on decomposition, increasing

21 evidence is demonstrating that carbon mineralisation can be influenced by the past resource

22 history, mainly through following two processes: (i) decomposer communities from recalcitrant

23 litter environments may have a wider functional ability to decompose a wide range of litter 
24 species than those originating from richer environments, i.e. the functional breadth (FB)

25 hypothesis; and/or (ii) decomposer communities may be specialized towards the litter they most

26 frequently encounter, i.e. the home-field advantage (HFA) hypothesis. Nevertheless, the

27 functional dissimilarities among contrasting microbial communities, which are generated by the

28 FB and the HFA, have rarely been simultaneously quantified in the same experiment, and their

29 relative contributions over time have never been assessed. To test these hypotheses, we

30 conducted a reciprocal transplant decomposition experiment under controlled conditions using

31 litter and soil originating from four ecosystems along a land-use gradient (forest, plantation,

32 grassland and cropland) and one additional treatment using ${ }^{13} \mathrm{C}$ labelled flax litter allowing us to

33 assess the priming effect (PE) in each ecosystem. We found substantial effects of LQ on carbon

34 mineralisation (more than two-thirds of the explained variance), whereas the contribution of the

35 soil type was fairly low (less than one-tenth), suggesting that the contrasting soil microbial

36 communities play only a minor role in regulating decomposition rates. Although the results on

$37 \mathrm{PE}$ showed that we overestimated litter-derived $\mathrm{CO}_{2}$ fluxes, litter-microbe interactions

38 contributed significantly to the unexplained variance observed in carbon mineralisation models.

39 The magnitudes of FB and HFA were relatively similar, but the directions of these mechanisms

40 were sometimes opposite depending on the litter and soil types. FB and HFA estimates

41 calculated on parietal sugar mass loss were positively correlated with those calculated on

42 enzymatic activity, confirming the idea that the interaction between litter quality and microbial

43 community structure may modify the trajectory of carbon mineralisation via enzymatic synthesis.

44 We conclude that although litter quality was the predominant factor controlling litter

45 mineralisation, the local microbial communities and interactions with their substrates can explain

46 a small $(<5 \%)$ but noticeable portion of carbon fluxes. 
48 Keywords: aboveground-belowground, functional equivalence, functional redundancy,

49 functional similarity, litter decomposition, local adaptation, microbial community structure,

50 plant-soil interactions.

\section{Introduction}

53

The decomposition of plant litter is one of the most important processes influencing the

55 global carbon cycle, the mineralisation of nutrients, soil fertility, and the formation of soil

56 organic matter in terrestrial ecosystems. Almost 40 years ago, Meentemeyer (1978) proposed

57 that climate and litter quality are the main factors explaining plant litter decomposition at the

58 global scale. In the decades since, many studies have confirmed this pattern at the continental

59 scale (e.g., Aerts 1997, Gholz et al. 2000, Trofymow et al. 2002, Powers et al. 2009), but the

60 factors contributing to the unexplained variation in local decomposition processes and their

61 relative contributions remain uncertain (Bradford et al. 2014). A variety of drivers modifying the

62 trajectory of decomposition rates have been proposed, including diversity effects (Heemsbergen

63 et al. 2004, Gessner et al. 2010), solar radiation (Austin and Vivanco 2006), the temporal

64 concordance between tree phenology and soil decomposers (Pearse et al. 2014), and the structure

65 of the soil fauna and microbial communities (Wall et al. 2008, Strickland et al. 2009a). It has

66 also been suggested that interactions between the litter quality and decomposer communities may

67 locally influence decomposition rates due to decomposers' different perceptions and/or

68 specialisations toward specific substrates (Hunt et al. 1988, Gholz et al. 2000, Strickland et al.

69 2009b). Nonetheless, important uncertainties remain regarding the magnitude and direction of 
70 these interactions (Ayres et al. 2006, Chapman and Koch 2007, Freschet et al. 2012). In

71 particular, little is known about the kinetics of litter-decomposer interactions over time (but see

72 Ayres et al. 2009a), and positive or negative effects may depend on the interactions between the

73 initial litter quality, the stage of decomposition, and the local decomposer community (Strickland

74 et al. 2009a, Wickings et al. 2012, Wallenstein et al. 2013). In this context of multiple biotic and

75 abiotic factors regulating the decomposition rate at a local scale, we focused on a set of

76 hypotheses addressing the effects of plant-soil interactions on carbon mineralisation during the

77 decomposition of plant litter in a variety of contrasting ecosystems (Fig. 1). The selected land-

78 use gradient, which ranges from cropland, plantation, and grassland to forest on a common soil

79 substratum and varies in vegetation cover and disturbance frequency, offers a great opportunity

80 to accurately assess the relative importance of substrate quality and microbial community on

81 litter decomposition.

First, the 'litter quality' (LQ) hypothesis suggests that the intrinsic physical and chemical

83 characteristics of leaf litter, commonly measured as the $\mathrm{C}: \mathrm{N}$ and lignin: $\mathrm{N}$ ratios or the quality of

84 various carbon forms, are the main predictors influencing the decomposition rate (Aber et al.

85 1990, Aerts 1997, Cornwell et al. 2008). In a reciprocal litter transplant study using 16 different

86 species across four different biomes, Makkonen et al. (2012) showed that a small subset of litter

87 traits explained most of the variation in litter mass loss, suggesting that the decomposition

88 process is largely independent of the local decomposer communities. Because of these "litter trait

89 controls', differences in carbon mineralisation rates during litter decomposition should result

90 from the higher consumption of easily degradable litters (e.g., rich in soluble and holocellulose

91 contents) and the persistence of recalcitrant litters that are more resistant to decay (e.g., rich in

92 lignin and secondary metabolites). For example, along a land-use gradient, grass litter, which 
93 represents an energy-rich and labile substrate, should decompose faster in all types of ecosystems

94 compared to the poorer and more recalcitrant forest litter (Fig. 1a). Support for this hypothesis is

95 derived from a multitude of decomposition studies in which a range of litter types were allowed

96 to decompose across a variety of ecosystems (e.g., Gholz et al. 2000, Hobbie et al. 2006,

97 Makkonen et al. 2012).

98 Second, the 'functional breadth' (FB) hypothesis stipulates that decomposer communities

99 from recalcitrant litter environments have a wider functional ability than those originating from

100 richer environments, meaning that they more efficiently decompose various litter types that vary

101 widely in their chemical and physical characteristics (van der Heijden et al. 2008, Keiser et al.

102 2011). Because of the past resource history that may influence whether microbial communities

103 are functionally 'broad' or 'narrow' (Keiser et al. 2014), differences in the carbon mineralisation

104 rates during litter decomposition should result from different catabolic capacities among

105 contrasted decomposer communities. Thus, all litter species should decompose faster in the

106 forest soil than in any other ecosystem because of a higher capability of the forest soil microbial

107 community to decompose a wide range of litter substrates (Fig. 1b). Consistent with this

108 hypothesis, Strickland et al. (2009b) demonstrated that poor and recalcitrant litter was

109 decomposed more efficiently by decomposer communities originating from forested habitats,

110 whereas easily degradable litter was decomposed equivalently by all communities of

111 decomposers from different types of ecosystems. These results indicate that microbial

112 communities may be functionally dissimilar for the degradation of recalcitrant litter substrates

113 and consequently that changes in ecosystem processes may also be strongly influenced by the

114 functional ability of distinct decomposer communities (Strickland et al. 2009a). 
116 faster in an area dominated by the plant species from which it derives (i.e., at home) rather than

117 in an area dominated by another plant species (i.e., away) (Gholz et al. 2000). Because of this

118 'local adaptation' of the decomposer community, differences in carbon mineralisation rates

119 during litter decomposition should result from the match between a litter type and its own

120 environment. For example, forest litter should decompose faster in forest soil, whereas wheat

121 litter should decompose faster in cropland soil (Fig. 1c). In agreement with this hypothesis,

122 numerous studies have documented that plant litters decompose fastest in their local environment

123 (e.g., de Toledo Castanho and de Oliveira 2008, Vivanco and Austin 2008, Strickland et al.

$1242009 a$, Wallenstein et al. 2010). Although the HFA hypothesis has generated great attention,

125 several empirical studies did not find any evidence of such affinity between litter and microbes at

126 home (Ayres et al. 2006, Gießelmann et al. 2011, St John et al. 2011, Veen et al. 2015), sparking

127 an important debate about the generalizability of this mechanism (see Austin et al. 2014 for a

128 review). This 'affinity effect' between decomposers and their substrates has been recently

129 amended with the 'substrate-matrix interaction' hypothesis (Freschet et al. 2012), which states

130 that the composition of the decomposer community should reflect the average quality of the litter

131 matrix rather than species-specific home litter effects, in particular in biomes dominated by

132 multiple and chemically contrasted plant species. Despite these recent advances, few studies

133 have addressed carbon dynamics over time in relation to simultaneous changes in litter quality,

134 the local microbial community, and their functional abilities, although such an effort is essential

135 for assessing the unexplained variation in decomposition rates caused by litter-microbe

136 interactions at the local scale. 
138 microbe interactions in a reciprocal transplant experiment of contrasting litters and their

139 associated soils originating from a land-use gradient (forest, plantation, grassland and cropland)

140 across a one-hectare plot. Because little is known about whether the previously described

141 mechanisms are transient or persistent over time, we specifically followed the kinetics of carbon

142 mineralisation over 202 days and 21 dates to better grasp the variability of responses generated

143 by the interactions between soil microbial communities and litter types. In order to ensure that

144 the mineralisation of 'older' organic matter via 'fresh' litter addition did not alter our conclusions

145 on litter-microbe interactions, we also measured the mineralisation of soil organic matter

146 following the addition of ${ }^{13} \mathrm{C}$ labelled flax litter (Linum usitatissimum L.) for assessing the

147 contribution of priming effect (PE) in each ecosystem. To investigate the triangular relationships

148 involving litter quality, the decomposer community and enzymatic activities for explaining the

149 observed affinity effects, we analysed at three time points (at 27, 97, and 202 days) the mass loss

150 rates of the main sugars within the cell wall, the microbial community structure via twenty-four

151 selected PLFA markers, and the activities of four hydrolytic enzymes. We employed a new

152 model recently developed by Keiser et al. (2014) that allowed us to simultaneously test our three

153 main hypotheses by calculating the estimated parameters for LQ, FB and HFA and their effects

154 on carbon mineralisation. Finally, by assessing the effects of these parameters on the mass loss

155 of parietal sugars and on enzymatic activities, we addressed for the first time whether the effects

156 of FB and HFA on carbon mineralisation depend on the functional ability of the soil decomposer

157 communities.

158

159 Methods 


\section{Microcosm design}

162

163 Litter and soil were collected from a one-hectare plot within the 'AgroParisTech' site,

164 Paris-Grignon $\left(48^{\circ} 50^{\prime} \mathrm{N}, 1^{\circ} 56^{\prime} \mathrm{E}\right)$. We identified four areas in close proximity to one another

165 representing the four different systems that were present in our study site, i.e., cropland $166\left(48^{\circ} 51^{\prime} 11.7 .8^{\prime}{ }^{\prime} \mathrm{N}, 1^{\circ} 56^{\prime} 15.5^{\prime \prime} \mathrm{E}\right)$, deciduous forest $\left(48^{\circ} 51^{\prime} 15.3^{\prime \prime} \mathrm{N}, 1^{\circ} 56^{\prime} 01.7^{\prime \prime} \mathrm{E}\right)$, grassland

$167\left(48^{\circ} 51^{\prime} 17.0^{\prime \prime} \mathrm{N}, 1^{\circ} 55^{\prime} 44.0^{\prime \prime} \mathrm{E}\right)$, and tree plantation $\left(48^{\circ} 51^{\prime} 16.4^{\prime \prime} \mathrm{N}, 1^{\circ} 55^{\prime} 30.4^{\prime \prime} \mathrm{E}\right)$. The shortest

168 and longest distances between two sites were 250 and $900 \mathrm{~m}$, respectively. Wheat (Triticum

169 aestivum L.), beech (Fagus sylvatica L.), fescue (Festuca arundinacea Schreb.), and black locust

170 (Robinia pseudoacacia L.) were the dominant plant species in each respective ecosystem. In the

171 forest and grassland ecosystems, which present greater plant diversity than the monospecific

172 wheat culture and black locust plantations, we selected sampling areas within nearly pure stands

173 to prevent litter mixing and difficulties in interpreting the results due to potential diversity

174 effects. Forest and plantation litters were collected as recently fallen leaf litter, grass litter was

175 collected as standing-dead material, and cropland litter was collected just after the wheat harvest

176 in October 2013. In the laboratory, all of the litter samples were sorted to remove the fruits,

177 seeds, and roots, cut into approximately $1 \mathrm{~cm}$ pieces using scissors, homogenised, and dried at

$17840^{\circ} \mathrm{C}$. Litter was sterilised by autoclaving $\left(121^{\circ} \mathrm{C}, 20 \mathrm{~min}\right)$ twice in succession to maximise the

179 chance that the decomposer communities were introduced only via the soil and not by the litter

180 material, but we acknowledge that autoclaving may have altered the initial litter chemistry. The

181 litter chemical quality was determined using standard methods after sterilisation (see Appendix

182 A for a detailed description of the litter chemical parameters and determination methods). 
183 Mineral soil was collected from three different areas in each ecosystem by digging $25 \times 25 \mathrm{~cm}^{2}$

184 holes to a depth of $10 \mathrm{~cm}$, representing three independent samples series per land-use type. The

185 soil was passed through a 2-mm sieve, homogenised, and then stored at $4^{\circ} \mathrm{C}$ until use (see

186 Appendix B for a detailed description of the soil characteristics).

187 The soil samples (100 g dry mass) were mixed with the litter samples at a rate equivalent

188 to $10 \mathrm{~g} \mathrm{C} \mathrm{kg}^{-1}$ dry soil (between 2.05 and $2.22 \mathrm{~g}$ of dry mass) in $850 \mathrm{ml}$ glass jars and incubated

189 for 202 days at $20^{\circ} \mathrm{C}$. Based on preliminary tests and previous incubation experiments (e.g.,

190 Bertrand et al. 2007, Amin et al. 2014), $2 \mathrm{~g}$ of litter was considered as the best compromise

191 between the need to retrieve enough material for our chemical analyses after 202 days of

192 decomposition and the quantity necessary for optimizing the stimulation of soil microbial

193 communities. The mixture was adjusted to and maintained at a potential of $-80 \mathrm{kPa}$, which

194 corresponds to $221-230 \mathrm{~g} \mathrm{~kg}^{-1}$ of air-dried-soil water content (approximately $50 \%$ water-holding

195 capacity) and favours microbial activity (Bertrand et al. 2007). The soil moisture was maintained

196 throughout the incubation period by weighing the microcosms twice per month and readjusting

197 with deionised water when necessary. We used a reciprocal transplant design (i.e., all of the litter

198 types crossed with all of the soil types) plus additional 'no-litter' soil samples. In total, 9

199 replicates per treatment were constructed, permitting the destructive harvest of replicates on 200 incubation days 27, 97, and 202 for chemical, enzymatic and microbial community analyses. On 201 each sampling date and for each microcosm, a subsample of the remaining litter material was 202 carefully retrieved, cleaned of soil particles, and dried at $37^{\circ} \mathrm{C}$ for parietal sugar and lignin 203 analyses. Two additional subsamples of soil and litter mixtures were immediately frozen at $20420^{\circ} \mathrm{C}$ for further PLFA analyses and enzymatic assays. 
208 Carbon mineralisation was measured in triplicate for each soil $\times$ litter type combination in 209 the presence of a $\mathrm{CO}_{2} \operatorname{trap}(15 \mathrm{ml}$ of $1 \mathrm{M} \mathrm{NaOH})$ at $[3,6,9,13,17,21$, and 27], [34, 41, 51, 62, 21073,85 , and 97], and [112, 126, 140, 154, 168, 182, and 202] days after the start of incubation.

211 Specifically, the microcosms harvested on days 27,97 , or 202 were the same microcosms from 212 which we measured the carbon mineralisation rates during the three periods, i.e., 3-27, 28-97, or 213 98-202 days of incubation. This measurement trend resulted in 21 sampling dates divided into 214 three incubation periods composed equally of 7 sampling dates. The carbon dioxide production 215 rates $\left(\mathrm{mg} \mathrm{C} \mathrm{kg}^{-1}\right.$ soil day $\left.{ }^{-1}\right)$ and cumulative carbon mineralisation ( $\mathrm{mg} \mathrm{C} \mathrm{kg}^{-1}$ soil) were corrected 216 for the contribution of the corresponding soil type by subtracting the carbon mineralisation of the 217 'no-litter' soil (except when 'raw data' are mentioned in the text). It should be noted that the 218 carbon mineralisation was analysed for all of the microcosms (i.e., 3 sets of 3 replicates) on day 21927 , whereas only 2 sets and 1 set of microcosms were collected on days 97 and 202, respectively, 220 since the first and second sets of microcosms had already been destructively harvested. The 221 concentrations of $\mathrm{CO}_{2}$ trapped in the $\mathrm{NaOH}$ solution were measured by continuous flow 222 colourimetry using an auto-analyser (TRAACS 2000, Bran \& Luebbe, Norderstedt, Germany).

\section{Priming effect}

227 in an airtight growth chamber in which conditions (air moisture, air temperature and 228 photoperiod) were monitored to mimic spring conditions. The plants were grown on rockwool 
229 plugs under hydroponic conditions using nutrient solutions as described by Devienne et al. 230 (1994). The plants were continuously labelled with ${ }^{13} \mathrm{C}$ by using the same ${ }^{13} \mathrm{CO}_{2}$ bottles

231 throughout the entire growth cycle. Flax stem was collected at maturity $\left(\delta^{13} \mathrm{C}=2870 \%\right.$, atom $\%$ 232 excess $=3.056)$, homogenised, incubated at a rate equivalent to $10 \mathrm{~g} \mathrm{C} \mathrm{kg}^{-1}$ dry soil $(2.13 \mathrm{~g}$ of 233 dry mass) and carbon mineralisation was measured as described above. Flax litter represented a 234 mid-range quality, characterized by intermediate content of nitrogen, lignin, and soluble 235 compounds and showed cumulative carbon mineralisation comprised between Gramineae and 236 woody plant species with an average of $5232 \mathrm{mg} \mathrm{C} \mathrm{kg}^{-1}$ soil (see Appendix $\mathrm{C}$ for more details).

238 solutions and the resulting precipitate of $\mathrm{BaCO}_{3}$ was separated by vacuum filtration (glass fiber 239 filter) and dried at $80^{\circ} \mathrm{C}$ for 8 hours. The $\mathrm{BaCO}_{3}$ precipitate was weighed in a tin cap with the 240 addition of a catalyst $\left(\mathrm{PbO}_{2}\right)$, and the isotope ratio ${ }^{13} \mathrm{C} /{ }^{12} \mathrm{C}$ of the precipitate was measured with 241 an elemental analyzer (Eurovector, Milan, Italy) coupled to a mass spectrometer (Delta S 242 Advantage, Thermo Fisher Scientific, Bremen, Germany). The priming effect (PE) was

243 calculated with the following equation:

$244 \mathrm{PE}=\left[{ }^{12+13} \mathrm{CO}_{2}\right.$-amended $-{ }^{13} \mathrm{CO}_{2}$-amended $]-{ }^{12} \mathrm{CO}_{2}{ }^{\text {ctrl }}$

245 where ${ }^{12+13} \mathrm{CO}_{2}$-amended and ${ }^{12} \mathrm{CO}_{2}{ }^{\text {ctrl }}$ are the cumulative amounts $\left(\mathrm{mg} \mathrm{kg}^{-1}\right)$ of mineralized 246 carbon in the soil with and without litters, respectively, and ${ }^{13} \mathrm{CO}_{2}$-amended represents the litter247 derived carbon.

249 Litter chemical analyses 
To characterise the parietal sugars initially and at days 27,97 , and 202, the plant litter

252 samples were subjected to a cell wall preparation process that consisted of extracting the neutral

253 detergent fibre (NDF) fraction as described by Goering and Van Soest (1970). The soluble

254 fraction was removed by boiling between 0.7 to $1 \mathrm{~g}$ of litter in deionised water at $100^{\circ} \mathrm{C}$ for 30

$255 \mathrm{~min}$ and then performing an extraction with a neutral detergent solution at $100^{\circ} \mathrm{C}$ for $60 \mathrm{~min}$ to

256 remove the cytoplasmic components and obtain the NDF fraction. All residues from the cell wall

257 preparations were dried for one week at $30^{\circ} \mathrm{C}$ and ground to $80 \mu \mathrm{m}$. The parietal sugars were

258 then analysed as previously described (Machinet et al. 2011). Briefly, $10 \mathrm{mg}$ of the NDF residue

259 was allowed to swell in $125 \mu \mathrm{l}$ of $12 \mathrm{M} \mathrm{H}_{2} \mathrm{SO}_{4}$ for $2 \mathrm{~h}$ at $20^{\circ} \mathrm{C}$ and was then subjected to acid

260 hydrolysis with $1 \mathrm{M} \mathrm{H}_{2} \mathrm{SO}_{4}$ for $2 \mathrm{~h}$ at $100^{\circ} \mathrm{C}$. The monosaccharides released by the acid

261 hydrolysis were separated by high-performance anion-exchange chromatography (HPAEC) on a

262 CarboPac PA-1 column (Dionex ICS 5000+, Thermo-Scientific, Sunnyvale, CA, USA). The

263 monosaccharide composition was analysed, and nine sugars were quantified using 2-deoxy-D-

264 ribose as an internal standard and standard solutions of the following neutral carbohydrates: L-

265 arabinose, D-glucose, D-xylose, D-galactose, L-rhamnose, D-mannose, L-fucose, D-galacturonic

266 acid and D-glucuronic acid. The parietal sugars were calculated as the sum of all of the

267 monosaccharides.

268 The lignin content of the litter subsamples was approximated as the acid-non-

269 hydrolysable residue remaining after sulphuric acid hydrolysis according to the Klason lignin

270 determination method (Monties 1984). Briefly, $300 \mathrm{mg}$ of litter was suspended in $3 \mathrm{ml}$ of $12 \mathrm{M}$

$271 \mathrm{H}_{2} \mathrm{SO}_{4}$ for $2 \mathrm{~h}$ at room temperature. The suspensions were then diluted to $1 \mathrm{M}$ with deionised

272 water, heated at $100^{\circ} \mathrm{C}$ for $3 \mathrm{~h}$ and filtered. The remaining litter was dried at $105^{\circ} \mathrm{C}$ and the ash 
273 content was determined after $4 \mathrm{~h}$ of combustion at $500^{\circ} \mathrm{C}$. The lignin content was calculated as

274 the mass difference before and after combustion.

275

276 Enzymatic activities

277

278

At days 27, 97, and 202, we used a method by Bell et al. (2013) to measure the potential

279 activity of four hydrolytic soil enzymes, which degrade a range of substrates that are common

280 constituents of organic matter. The following enzymes were selected to represent the degradation

281 of C-rich substrates: $\beta$-1,4-glucosidase, $\beta$-D-cellobiosidase, $\alpha$-glucosidase, and $\beta$-xylosidase (see

282 Appendix D for details regarding the initial enzymatic activity of each system). In brief, the

283 assays were conducted by homogenising $2.75 \mathrm{~g}$ of the soil-litter mixture in $91 \mathrm{ml}$ of $50 \mathrm{mM}$

284 TRIS buffer (pH 7.8 for forest or grassland, $\mathrm{pH} 8.1$ for cropland and plantation) in a blender for

$2851 \mathrm{~min}$. The soil slurries were then added to a 96-deep-well microplate using an eight-channel

286 repeat pipettor. Additional quench control replicates of the soil slurry and 4-methylumbelliferone

287 (MUB) standard curves $(0-100 \mu \mathrm{M}$ concentrations) were included with each sample. The soil

288 slurries were incubated with fluorometric substrates for $3 \mathrm{~h}$ at $25^{\circ} \mathrm{C}$. After the incubation period,

289 the plates were centrifuged for $20 \mathrm{~min}$ at $3000 \mathrm{rpm}$, after which $250 \mu 1$ of supernatant was

290 transferred from each well into a black, flat-bottomed 96-well plate that was scanned using a

291 microplate reader (SpectraMax Gemini, Molecular Devices, CA, USA) with an excitation

292 wavelength of $365 \mathrm{~nm}$ and an emission wavelength of $450 \mathrm{~nm}$. All enzymatic activities were first

293 calculated in $\mathrm{nmol} \mathrm{g}^{-1}$ soil $\mathrm{h}^{-1}$ and were then corrected for the contribution of the corresponding

294 soil type by subtracting the enzyme activities of the 'no-litter' soil. These values were

295 subsequently integrated over time ( $\mathrm{mmol} \mathrm{kg}^{-1}$ soil) following Sinsabaugh et al. (2002). 
297 Microbial community structure

298

The microbial community structure was determined at days 27, 97, and 202 by an

300 analysis of the group-specific phospholipid fatty acids (PLFAs) according to the protocol

301 described by Fanin et al. (2014) (Appendix D for details regarding the initial community 302 composition of each system). From each microcosm, a $10 \mathrm{~g}$ frozen soil subsample was used for 303 total lipid extraction in a single-phase mixture of chloroform:methanol:phosphate buffer at $\mathrm{pH}$ 3047.4 (1:2:0.8 by vol.), eluted selectively, and subjected to a mild methanolysis. The resulting

305 PLFAs were analysed on a gas chromatograph equipped with a flame ionisation detector 306 (Agilent 6890, Agilent Technologies, Palo Alto, USA) with a $60 \mathrm{~m} \times 0.25 \mathrm{~mm} \times 0.15 \mu \mathrm{m} \mathrm{DB}-23$

307 column (Agilent Technologies, Palo Alto, USA) and by gas chromatography-mass spectrometry

308 (Shimadzu QP2010 plus, Shimadzu Corporation, Suzhou, China). We retained the following 24

309 PLFAs as indicators of the microbial community structure: branched and saturated PLFAs i15:0,

310 a15:0, i16:0, i17:0, and a17:0 (Gram-positive bacteria); mono-unsaturated and cyclopropyl

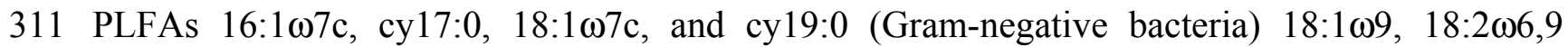

312 (fungi), 10me-16:0 and 10me-18:0 (Actinobacteria); and i14:0, 14:0, 15:0, 16:0, 17:0, i18:0,

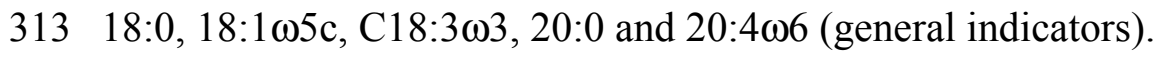

315 Data analysis

316

317 To examine the effects of the soil and litter types on the cumulative carbon

318 mineralisation, we performed a two-way ANOVA using the raw (total cumulative carbon 
319 mineralisation) or net data (cumulative carbon mineralisation corrected using 'no-litter' soils).

320 We then individually analysed the net mineralisation rates for each litter type using linear mixed

321 models in which the soil type and time were treated as fixed effects and were allowed to interact.

322 The microcosm identity was included as a random effect to account for the repeated sampling of

323 the microcosms across time. Using Bray-Curtis dissimilarity matrices, we ran non-metric

324 multidimensional scaling (NMDS) to visualise the differences in structure and catabolic ability

325 of the microbial community (as relative proportions of PLFAs and of the four enzymatic

326 activities) and then performed permutational multivariate ANOVAs to test the significance of the

327 litter type, soil type, and time for explaining the observed variations.

328 The relative contribution of the litter quality, functional breadth, and home-field

329 advantage in explaining the carbon mineralisation was estimated using the model developed by

330 Keiser et al. (2014). This model states that carbon mineralisation $\left(Y_{i}\right)$ is equal to litter ability $\left(\beta_{l}\right)$

331 plus soil ability $\left(\gamma_{s}\right)$ plus a home interaction term $\left(\eta_{h}\right)$ :

$$
Y_{i}=\alpha+\sum_{l=1}^{N} \beta_{l} \operatorname{Litter}_{l_{i}}+\sum_{s=1}^{M} \gamma_{s} \text { Soil }_{s_{i}}+\sum_{h=1}^{k} \eta_{h} \text { Home }_{h_{i}}+\varepsilon_{i}
$$

332

333 where $Y i$ is the carbon mineralisation for observation $i, \beta_{l}$ is the ability of litter species $l$ (from

334 species 1 to $N$ ), $\gamma_{s}$ is the ability of the soil community $s$ (from community 1 to $M$ ), $\eta_{h}$ is the HFA

335 of $h$ (from home combinations 1 to $K$ ), and $\mathrm{Home}_{h}=\operatorname{Litter}_{l} *$ Soil $l_{s}$ when $l$ and $s$ are home-field

336 pairings. The parameters to be estimated are $\beta_{l}, \gamma_{s}$ and $\eta_{h}$. The intercept term is defined by $\alpha$ and

337 represents the average carbon mineralisation rate for all observations in the dataset after

338 controlling for litter, soil and home-field pairings. Negative parameter estimates indicate lower

339 carbon mineralisation than the average rate observed across all samples in the device. The error

340 term is defined by $\varepsilon$. Using this model, we calculated a quality index (LQ), the ability of soil 
341 microbial communities (FB), and the interactions between litter and soil (HFA) on the net

342 cumulative carbon mineralisation. Keiser's model was also used to determine the relative

343 contributions of FB $\left(\gamma_{s}\right)$ and HFA $\left(\eta_{h}\right)$ in explaining the sugar mass loss (computed for the sum

344 of all parietal sugars) and enzymatic activities (computed for the sum of the four net integrated

345 enzymatic activities). We then explored the correlations between the parameter estimates for FB

346 and HFA on the parietal sugar mass loss and on the net integrated enzymes to visualise potential

347 relationships between these two sets of variables. All of the statistical tests were performed using

348 R software (version 3.1.1, The R Foundation for Statistical Computing, Vienna, Austria) and

349 SAS software (version 9.0, SAS institute, NC, USA).

350

\section{Results}

352

353 Litter quality and carbon mineralisation

356 ratio varied by almost eightfold, ranging from 18.4 to 140.9 between the plantation $(R$.

357 pseudoacacia) and cropland (T. aestivum) litters, respectively, whereas the bulk litter lignin

358 concentration varied by a factor of 2.5 between the forest ( $F$. sylvatica) and grass ( $F$.

359 arundinacea) litters (39.3\% and $15.5 \%$, respectively; see Appendix A for more details). The

360 variability of the litter chemistry was particularly apparent when considering parietal sugars,

361 especially between forest and cropland litter types, with more than threefold variation in the

362 glucose and xylose concentrations. The polyphenol contents were the highest in the forest and 
363 plantation litters, as was the lignocellulose index, ranging from 0.22 and 0.24 for cropland and 364 grass litters to 0.65 and 0.67 for forest and plantation, respectively.

365 The cumulative carbon mineralisation over 202 days varied according to the litter types, 366 ranging from 3463 to $6649 \mathrm{mg} \mathrm{C} \mathrm{kg}^{-1}$ of soil for the forest and grassland litters, respectively (Fig.

367 2A). The variation in the average cumulative carbon mineralisation between the soil types was,

368 however, less important than was that observed between the litter species, with a minimum of $3694237 \mathrm{mg} \mathrm{C} \mathrm{kg}^{-1}$ for the cropland soil and a maximum of $6287 \mathrm{mg} \mathrm{C} \mathrm{kg}^{-1}$ for the forest soil (Fig.

370 2B, see also Appendix E for details on the control soils). Priming effect (PE) varied over time 371 with a maximum of $232 \mathrm{mg} \mathrm{C} \mathrm{kg}^{-1}$ on average after 202 days (Fig. 2C, Appendix C). After a 372 mineralisation flush during the first 7 days, PE increased steadily for cropland and plantation 373 soils while it was negative for grassland and forest soils, meaning that the SOM mineralisation 374 was higher in the control than in the ${ }^{13} \mathrm{C}$ litter-amended soils. Although PE increased in the forest 375 soil to similar levels than in cropland and plantation soils after 97 days of decomposition, 376 grassland soil always showed lower PE, with a difference of $78 \mathrm{mg} \mathrm{C} \mathrm{kg}^{-1}$ on average compared 377 with the three other ecosystems (Fig. 2C). Overall, PE corresponded to 3.6 to $6.6 \%$ of net carbon 378 mineralisation between 27 and 202 days.

379 Using raw data for the total cumulative carbon mineralisation measured in the four 380 ecosystems, we observed that the average percentage of variance explained by the soil type 381 increased during the course of the incubation, ranging from of $9.6 \%$ at the beginning to $32.1 \%$ at 382 the end of the experiment. By contrast, the average contribution of the litter type decreased from 38389.3 to $66.9 \%$ during the same time (Table 1). However, when considering the net data 384 (cumulative carbon mineralisation corrected by 'no-litter' soils), the soil type explained only 1.9 385 to $4.0 \%$ of the variation in the net carbon mineralisation over 202 days, suggesting that this effect 
386 is more subtle when the initial soil variation among ecosystem types is considered (Table 1). In 387 this latter model, the litter species explained $94 \%$ of the average variance of carbon 388 mineralisation independently of the sampling date (Table 1). Among the different litter traits, the 389 lignin: $\mathrm{N}$ and $\mathrm{C}: \mathrm{N}$ ratios were poor predictors of the mineralisation rates $(p>0.05$, Appendix F).

390 By contrast, the lignocellulose index (LCI) showed strong negative correlations with the carbon 391 mineralisation rates for each litter type individually but also globally using the entire dataset $\left(r^{2}\right.$ $392=0.47, p<0.05$, Appendix F). Finally, when the effect of each litter type was investigated 393 separately over the course of the incubation, the dynamics of the net carbon mineralisation rates 394 of the cropland, forest and plantation litter types were influenced by the soil type and by a soil 395 type $\times$ time interaction that decreased from 0-27 to 98-202 days (Table 2). The soil net carbon 396 mineralisation rates for the grass litter showed only an effect of the soil type for the period 28-97 397 days and significant soil type $\times$ time interactions at 0-27 and 98-202 days (Table 2, see also 398 Appendix $\mathrm{G}$ for the general model).

399

400 Microbial community structure and enzymatic production

401

402 Most of the PLFA markers showed significant differences among the soil and litter type 403 combinations, indicating that the soil microbial community structure was affected by multiple 404 parameters (Fig. 3A, Table 3). Over the course of the incubation, the soil type and the identity of 405 the decomposing leaf litter were the most significant factors, explaining an average of $36 \%$ and $40618 \%$, respectively, of the variability in the community structure (Table 3). To a lesser extent, 407 time (12\%) and its interaction with the soil type (9\%) or litter type (4\%) also explained a 408 significant part of the observed variation. Consistent with the reported differences in the 
409 microbial community structure, the ordination plot from NMDS clearly distinguished the

410 communities from the four soil types (Fig. 3A). The microbial communities were plotted

411 according to a pattern in which the first axis depicted the land-use gradient from cropland to

412 forest and the second axis separated the agro-systems (cropland and plantation) from the less

413 intensively managed ecosystems (forest and grassland).

414 Similar to what was observed for the microbial community structure, we found that the

415 soil type was the most important driver, explaining $28 \%$ of the variation in the enzymatic activity

416 (Fig. 3B, Table 3). The soil type was visually confirmed as a main driver of enzymatic activity

417 when the NMDS plot was observed, although this result was clearer from the PLFA data. In the

418 NMDS plot, a clear segregation occurred along the first two axes between the plantation and

419 cropland soils on the one hand (down left), and the forest and grassland soils on the other hand

420 (top right) (Fig. 3B). The litter types and their interaction with time or soil only slightly

421 influenced the patterns of enzyme activities in the different soil-litter type combinations (Table

422 3B). In contrast, time and its interaction with the soil type explained $25 \%$ and $19 \%$ of the

423 variability in enzymatic patterns, respectively.

424

425 Major controls of litter carbon mineralisation and their relations to enzymatic activity

426

427

When estimating the $\beta_{l}(\mathrm{LQ}), \gamma_{s}(\mathrm{FB})$, and $\eta_{h}$ (HFA) metrics from the net carbon

428 mineralisation data, we found that $\beta_{l}$ was the metric that showed the largest variation (Fig. 4),

429 with values ranging from -1725 to $+1426 \mathrm{mg} \mathrm{C}$ mineralised $\mathrm{kg}^{-1}$ soil on average across the soil

430 and litter type combinations. The grass and cropland litters showed the highest LQ index

431 compared to the plantation and forest litters (Fig. 4A), confirming that more labile litter types 
432 degraded fastest across all of the ecosystems (Fig. 2A). Overall, we observed an initial and rapid

433 increase or decrease in $\beta_{l}$ for the grass and forest litters, followed by a slow decline in carbon

434 mineralisation over the incubation period (Fig. 4A). Meanwhile, a transition period occurred for

435 the cropland and plantation litters between 0 and 27 days, followed by a regular increase or

436 decrease in $\beta_{l}$, suggesting that the notion of litter quality for the soil decomposers may vary from

437 the short to the long term (Fig. 4A). When estimating the functional ability $\gamma_{s}$ that varied from -

438249 to $+364 \mathrm{mg} \mathrm{C}$ mineralised $\mathrm{kg}^{-1}$ soil, we observed that the 'ability' of decomposer

439 communities was highest and increased during the experiment for the forest soil (Fig. 4B). To a

440 lesser extent, the microbial community from the grassland soil also displayed positive $\gamma_{s}$ values,

441 with an increasing functional ability after a time lapse of approximately 100 days. In contrast, the

442 plantation and cropland soil types presented negative $\gamma_{s}$ values over the course of the incubation

443 experiment, indicating that these communities were unable to degrade a wide range of

444 qualitatively contrasting litter types (Fig. 4B). Finally, when evaluating whether a litter type

445 decomposed faster in an area dominated by the plant species from which it derived, we observed

446 an increasing affinity effect $\eta_{h}$ when the plantation soil microbial community matched its own

447 litter (Fig. 4C). Similarly, we found a positive $\eta_{h}$ between the grass litter and its own

448 environment, but this effect was transient over time and decreased after 140 days. No significant

449 HFA was found for the forest ( $p>0.05$ for the whole incubation period), and a disadvantage to

450 decomposing at home was found for the cropland litter, indicating that this litter type

451 decomposed more rapidly elsewhere than in its own environment (Fig. 4C).

452 When calculating the parameter estimates corresponding to the effects of $\mathrm{FB}\left(\gamma_{s}\right)$ and

453 HFA $\left(\eta_{h}\right)$ on the parietal sugar mass loss and net integrated enzymes, we observed positive

454 correlations between these two parameters across the various systems, indicating that a higher 
455 'functional ability' or 'affinity effect' on the decomposition process was related to a higher

456 enzymatic activity (Fig. 5, see also Appendix H for more details). In agreement with the carbon

457 mineralisation results, we observed positive $\gamma_{s}$ estimates for both the enzymatic activity and

458 sugar mass loss in the forest ecosystem, whereas the $\eta_{h}$ estimates were highest in the plantation

459 and grassland (Fig. 5). Specifically, the positive effects that FB and HFA had on parietal sugars

460 were mainly related to xylose and glucose dynamics during the early phase of decomposition,

461 whereas after 100 days of decomposition, lignin appeared to increase in importance as a factor

462 explaining the FB and HFA effects (Appendix I).

463

\section{Discussion}

465

466

Little is known regarding how the triangular interactions involving litter quality, the

467 decomposer community, and enzymatic activities can modify the trajectory of carbon dynamics

468 within a land-use gradient. To quantify the relative contributions of litter quality (LQ), functional

469 breadth (FB), and home field advantage (HFA) (Fig. 1), we implemented a reciprocal litter-soil

470 transplant decomposition experiment over 202 days. Despite the relatively similar decomposition

471 patterns across all soil-litter combinations, we found a twofold variation in the magnitude of

472 carbon mineralisation among the most chemically contrasting litter types at the end of the

473 incubation period (Fig. 2A), and distinct mineralisation rates for a given litter type incubated

474 with different soil inoculums (Table 2). Our results confirm that litter decomposition is mainly

475 influenced by litter quality, but indicate that the local microbial communities and interactions

476 with their substrates also explained a subtle $(<5 \%)$ but significant part of the variation in carbon

477 mineralisation (Table 1). Neither the amplitude nor the ranking of the priming effect (PE) 
478

479

480

481

482

483

484 Litter quality as a major control of carbon mineralisation

In agreement with our first hypothesis, the litter quality consistently explained more than

487 two-thirds of the carbon mineralisation, confirming that litter traits are the best predictors of

488 carbon dynamics (Makkonen et al. 2012, Cleveland et al. 2014). In contrast to the often assumed

489 relevance of the bulk nitrogen concentration or the lignin: $\mathrm{N}$ ratio of leaf litter, we found that the

490 variability in the carbon mineralisation rates among the different litter species was primarily

491 explained by the degree of recalcitrance of plant cell walls (Appendix F). These results suggest

492 that the complexity of the cell wall network can retard or enable the access of microorganisms to

493 easily degradable litter compounds and that simple estimators of the cell wall structure such as

494 the lignocellulose index (LCI) are useful indicators for assessing mineralisation rates using

495 predictive models at a local scale (Moorhead and Sinsabaugh 2006, Moorhead et al. 2014).

496

497 Testing the functional importance of microbial communities

498

499 Whether contrasting microbial communities are functionally equivalent regarding

500 ecosystem processes remains an essential issue for our prediction of the carbon balance along a 
501 land-use gradient. Overall, the soil type explained 9 to $32 \%$ of the variation in carbon

502 mineralisation during the course of the experiment (Table 1). However, when accounting for the

503 initial variability among the different ecosystems, the soil type explained only 2 to $4 \%$ of the

504 variation, suggesting that the response induced by the litter-microbe interactions was smaller in

505 our study than in other reports (Ayres et al. 2009b). The PE increased on average from 57 to 232

$506 \mathrm{mg} \mathrm{C} \mathrm{kg}^{-1}$ between 27 to 202 days, meaning that we overestimated litter-derived $\mathrm{CO}_{2}$ fluxes by

5073.6 to $6.6 \%$ in our models. In addition, PE was lower in grassland soils over the course of the

508 incubation experiment (Fig. 3C), indicating that caution must be taken when considering the

509 variation of litter-microbe interactions between grassland and the other soil types. However, the

510 relative consistency among soil types $(\mathrm{CV}=27 \%)$ explaining 0.03 to $1.18 \%$ in the variation in

511 net carbon mineralisation suggest that other factors besides PE also significantly influenced the

512 variation in decomposition rates.

513 Among the potential mechanisms to explain the responses induced by plant-soil

514 interactions, microorganisms may differ in their abilities to degrade contrasting litter species, i.e.,

515 in their FB (Keiser et al. 2014). In agreement with this second hypothesis, all of the tested litter

516 types decomposed more rapidly in the forest soil (Fig. 4B), confirming that microbial

517 communities originating from forested habitats display a greater ability to degrade various

518 substrates compared to those originating from more labile litter environments. Although we

519 cannot substantiate the notion that litter quality is 'in the eye of the beholder' (Strickland et al.

$5202009 b$ ), our results confirm that contrasting microbial communities may differ in their functional

521 abilities for decomposing various litter species (Strickland et al. 2009a). More importantly,

522 investigating the temporal dynamics of carbon mineralisation allowed us to determine that the

523 capacities of soil microbes are not set in stone. For example, the FB of the grassland microbial 
524 community, which had not faced complex substrates in their recent history, became positive and

525 increased steadily after 100 days (Fig. 4B). This result is particularly surprising given that the

526 fingerprint of the past resource is often invoked to explain plant-microbe interactions, suggesting

527 that additional mechanisms may influence the ability of a community to be functionally 'broad'

528 or 'narrow'. Although we cannot judge with certainty, the gene and protein expression, the

529 physicochemical characteristics of the surrounding environment, the diversity of soil

530 decomposers, and/or the presence of specific groups of decomposers may all explain the

531 functional ability dynamics. An alternative explanation would be that although we consciously

532 selected one species in almost pure stands for the ecosystems of grassland and forest, microbial

533 communities from these two ecosystems encountered a wider variety of chemical substrates than

534 did those originating from 'agro-systems', which likely influenced the contrasting functional

535 abilities observed among the four different soil types.

536 Another way to address functional dissimilarity between contrasting microbial

537 communities is the HFA hypothesis, which investigates whether microbes decompose litter that

538 is derived from a 'home' site more efficiently than litter that is derived from a 'away' site (Gholz

539 et al. 2000). Here, although the forest litter decomposed fastest in its own environment, we did

540 not find any evidence for an HFA effect in the forest soil because all of the litters decomposed

541 proportionally more rapidly in this ecosystem. Although the interpretation of HFA results should

542 be treated with caution since their variability is greater than that of LQ and FB, we found a small

543 positive HFA when the plantation and grassland litters matched their own environment,

544 indicating that soil microbial communities originating from these two environments were 'pre-

545 adapted' to decomposing substrates they were accustomed to encountering (Fig. 4C).

546 Counterintuitively, we demonstrated here that HFA is not systematically greater with increasing 
547 litter recalcitrance and that 'affinity effects' between microorganisms and their resources can

548 also be observed on more labile substrates. This idea has been recently supported by a meta-

549 analysis of 125 reciprocal litter transplants, in which Veen et al. (2014) concluded that HFA

550 effects were not related to particular litter types but were stronger when the litter quality between

551 'home' and 'away' sites was more dissimilar.

552

553 Microbial community structure and enzymatic activities: how can we explain the functional

554 dissimilarity?

555

556 To date, functional dissimilarities of soil microbial communities generated by FB and

557 HFA have not been separately quantified (but see Keiser et al. 2014), and our study is one of the

558 first to determine their relative contribution over time. Here, we found that the magnitude of

559 these two mechanisms was similar but that the directions of these effects were, in some cases,

560 opposite depending on both the litter and soil types (Fig. 4). The functional dissimilarity

561 generated by the effects of FB and HFA on parietal sugar mass loss were closely linked to soil

562 enzymes (Fig. 5), suggesting that the extracellular enzymatic activities are the main driver of the

563 interactions between litter quality and the decomposer communities. Surprisingly, despite the

564 large variations in microbial groups among the different ecosystems (Fig. 3A), we did not find

565 any direct relationship between the PLFA-based community structure and the hydrolytic enzyme

566 production. This result begs the question as to whether the relationship between the composition

567 of soil communities and the enzymatic synthesis is causal at the local scale. Similarly, Purahong

568 et al. (2014) recently demonstrated a decoupling between the microbial community structure and

569 hydrolytic, but not oxidative, enzymatic activities. At minimum, these data indicate that the 
570 enzymes necessary for degrading complex molecules are under the direct control of specific

571 groups of decomposers (i.e. fungi), and thus that any effect of community structure on

572 decomposition should be accentuated when one is interested in more recalcitrant leaf litter

573 compounds (Wallenstein et al. 2013). In agreement with this theory, we found that in most of the

574 litters presenting positive plant-soil interactions, lignin generally exhibited greater FB and HFA

575 effects compared to more labile monosaccharides after an approximately 100-day delay (see

576 Appendix I). Consequently, because contrasting microbial communities can change the course of

577 the decomposition process (Wickings et al. 2012), we believe that models predicting carbon

578 mineralisation should include parameters that explicitly represent the variability in the functional

579 abilities of decomposers (Treseder et al. 2012). However, although we excluded all the major

580 groups of macrofauna by sieving, we cannot ignore that the variability in micro- and mesofauna

581 diversity may have also contributed to the plant-soil interactions. Because higher trophic levels

582 have been shown to largely contribute to the interaction between litter and decomposer

583 communities, particularly in the poorest sites (e.g., Milcu and Manning 2011, Perez et al. 2013),

584 increasing the diversity of decomposers in the field will likely reveal a more complex situation

585 than that observed in our microcosm experiment.

586

587 Conclusions

588

589 Our fully factorial microcosm experiment provides new insight into the relative effects of

590 litter quality and microbial community on decomposition rates. The effect of soil type on carbon

591 mineralisation suggests that microbial communities have a subtle but significant role in

592 regulating decomposition rates. In particular, the mass loss of various parietal compounds in a 
593 given litter type can vary strongly between microbial communities from contrasting soil types.

594 Whether microbial diversity or soil physico-chemical properties are directly responsible for the

595 local variability observed in enzymatic activities nevertheless remains a complex question. In

596 other words, if microbial diversity is critical to enzymatic synthesis, then the absence of specific

597 groups due to ecosystem disturbance might have substantial impacts on the local carbon fate. If

598 not, enzymatic activity across various lineages of soil organisms should converge to optimise

599 resource acquisition and thus the functional traits of soil microbes would be more relevant than

600 their identity for predicting the ecosystem processes (Talbot et al. 2014). However, the relatively

601 small amount of variation that was explained by the litter-microbe interactions compared to that

602 which was explained by litter quality suggests that the composition of the microbial community

603 plays only a minor role in regulating the decomposition rates along our land use gradient. This

604 result questions the relevance of increasing efforts to understand the role of resource-consumer

605 interactions during litter decomposition in various ecosystems. Although this issue is

606 challenging, more attention should be paid to determining whether fundamental knowledge about

607 microbial diversity will considerably improve our predictions of carbon mineralisation and

608 enzymatic activities.

609

\section{Acknowledgments}

611

612 We thank Gonzague Alavoine for the management of the incubation experiment; Pascal

613 Thiebeau for his help with litter sampling; Sylvie Millon, Manon Gaddi, Antoine Portelette, and

614 Jorge Lebrato Mejijas for their highly appreciated laboratory assistance; Olivier Delfosse and

615 Marie Sauvadet for their help during microcosm destruction; Sylvie Recous and Gwenaëlle 
616 Lashermes for the fruitful discussions; and the reviewers for their constructive comments that

617 helped to improve the manuscript. We also thank the 'Office National des Forêts' (ONF) for

618 access to the black locust plantation and the 'Ferme Expérimentale de Grignon' for authorising

619 the sampling of the different 'AgroParisTech' sites. The microcosm experiment, chemical

620 analyses and enzymatic assays were performed at the laboratory 'Fractionnement AgroRessource

621 et Environnement' in Reims, and the PLFA analyses were performed at the 'Plate-Forme

622 d'Analyses Chimiques en Ecologie', PACE, technical facility of the Laboratoire d'Excellence

623 'Centre Méditerranéen de 1'Environnement et de la Biodiversité' in Montpellier. This study was

624 financially supported by the National Institute of Agronomic Research (INRA), the region

625 Champagne Ardennes and the EPRC project.

626

627 References

628

629 Aber, J. D., J. M. Melillo, and C. A. McClaugherty (1990) Predicting long-term patterns of mass

630 loss, nitrogen dynamics, and soil organic matter formation from initial fine litter

631 chemistry in temperate forest ecosystems. Canadian Journal of Botany 68: 2201-2208.

632 Aerts, R. 1997. Climate, leaf litter chemistry and leaf litter decomposition in terrestrial

633 ecosystems: a triangular relationship. Oikos:439-449.

634 Amin, B. A. Z., B. Chabbert, D. Moorhead, and I. Bertrand. 2014. Impact of fine litter chemistry

635 on lignocellulolytic enzyme efficiency during decomposition of maize leaf and root in

$636 \quad$ soil. Biogeochemistry 117: 169-183.

637 Austin, A. T., and L. Vivanco. 2006. Plant litter decomposition in a semi-arid ecosystem

638 controlled by photodegradation. Nature 442:555-558. 
639 Austin, A. T., L. Vivanco, A. González-Arzac, and L. I. Pérez. 2014. There's no place like home?

640 An exploration of the mechanisms behind plant litter-decomposer affinity in terrestrial

$641 \quad$ ecosystems. New Phytologist 204:307-314.

642 Ayres, E., K. M. Dromph, and R. D. Bardgett. 2006. Do plant species encourage soil biota that

643 specialise in the rapid decomposition of their litter? Soil Biology and Biochemistry

$644 \quad 38: 183-186$.

645 Ayres, E., H. Steltzer, S. Berg, and D. H. Wall. 2009b. Soil biota accelerate decomposition in 646 high-elevation forests by specializing in the breakdown of litter produced by the plant 647 species above them. Journal of Ecology 97:901-912.

648 Ayres, E., H. Steltzer, B. L. Simmons, R. T. Simpson, J. M. Steinweg, M. D. Wallenstein, N.

650

651 Mellor, W. J. Parton, J. C. Moore, and D. H. Wall. 2009a. Home-field advantage accelerates leaf litter decomposition in forests. Soil Biology and Biochemistry 41:606-

655 Bertrand, I., O. Delfosse, and B. Mary. 2007. Carbon and nitrogen mineralization in acidic, 656 limed and calcareous agricultural soils: Apparent and actual effects. Soil Biology and $657 \quad$ Biochemistry 39:276-288.

658 Bradford, M. A., R. J. Warren Ii, P. Baldrian, T. W. Crowther, D. S. Maynard, E. E. Oldfield, W. 659 R. Wieder, S. A. Wood, and J. R. King. 2014. Climate fails to predict wood

660 decomposition at regional scales. Nature Climate Change 4:625-630. 
661 Cleveland, C. C., S. C. Reed, A. B. Keller, D. R. Nemergut, S. P. O’Neill, R. Ostertag, and P. M.

662 Vitousek. 2014. Litter quality versus soil microbial community controls over

663 decomposition: a quantitative analysis. Oecologia 174:283-294.

664 Cook, F. J., and V. A. Orchard. 2008. Relationships between soil respiration and soil moisture.

665 Soil Biology and Biochemistry 40:1013-1018.

666 Cornwell, W. K., J. H. Cornelissen, K. Amatangelo, E. Dorrepaal, V. T. Eviner, O. Godoy, S. E.

667 Hobbie, B. Hoorens, H. Kurokawa, and N. Pérez-Harguindeguy. 2008. Plant species traits

668 are the predominant control on litter decomposition rates within biomes worldwide.

$669 \quad$ Ecology letters 11:1065-1071.

670 de Toledo Castanho, C., and A. A. de Oliveira. 2008. Relative effect of litter quality, forest type

671 and their interaction on leaf decomposition in south-east Brazilian forests. Journal of

$672 \quad$ Tropical Ecology 24:149-156.

673 Devienne, F., B. Mary, and T. Lamaze. 1994. Nitrate transport in intact wheat roots: II. Long-

674 term effects of $\mathrm{NO} 3-$ concentration in the nutrient solution on $\mathrm{NO}_{3}-$ unidirectional fluxes

675 and distribution within the tissues. Journal of Experimental Botany 45:677-684.

676 Fanin, N., S. Hättenschwiler, and N. Fromin. 2014. Litter fingerprint on microbial biomass,

677 activity, and community structure in the underlying soil. Plant and soil 379:79-91.

678 Freschet, G. T., R. Aerts, and J. H. Cornelissen. 2012. Multiple mechanisms for trait effects on

679 litter decomposition: moving beyond home-field advantage with a new hypothesis.

$680 \quad$ Journal of Ecology 100:619-630.

681 Gessner, M. O., C. M. Swan, C. K. Dang, B. G. McKie, R. D. Bardgett, D. H. Wall, and S.

682 Hättenschwiler. 2010. Diversity meets decomposition. Trends in Ecology \& Evolution

$683 \quad 25: 372-380$. 
684 Gholz, H. L., D. A. Wedin, S. M. Smitherman, M. E. Harmon, and W. J. Parton. 2000.

685 Long-term dynamics of pine and hardwood litter in contrasting environments: toward a 686 global model of decomposition. Global Change Biology 6:751-765.

687 Gießelmann, U. C., K. G. Martins, M. Brändle, M. Schädler, R. Marques, and R. Brandl. 2011.

688 Lack of home-field advantage in the decomposition of leaf litter in the Atlantic Rainforest 689 of Brazil. Applied Soil Ecology 49:5-10.

690 Goering, H. K., and P. J. Van Soest. 1970. Forage fiber analyses (apparatus, reagents, 691 procedures, and some applications). ARS-USDA Washington DC.

692 Heemsbergen, D., M. Berg, M. Loreau, J. Van Hal, J. Faber, and H. Verhoef. 2004. Biodiversity 693 effects on soil processes explained by interspecific functional dissimilarity. Science $694 \quad 306: 1019-1020$.

695 Hunt, H., E. Ingham, D. Coleman, E. Elliott, and C. Reid. 1988. Nitrogen limitation of 696 production and decomposition in prairie, mountain meadow, and pine forest. Ecology 697 69:1009-1016.

698 John, M. G. S., K. H. Orwin, and I. A. Dickie. 2011. No ‘home’versus 'away'effects of 699 decomposition found in a grassland-forest reciprocal litter transplant study. Soil Biology and Biochemistry 43:1482-1489.

701 Keiser, A., M. Strickland, N. Fierer, and M. Bradford. 2011. The effect of resource history on the 702 703 functioning of soil microbial communities is maintained across time. Biogeosciences 8:

704 Keiser, A. D., D. A. Keiser, M. S. Strickland, and M. A. Bradford. 2014. Disentangling the 705 mechanisms underlying functional differences among decomposer communities. Journal 706 of Ecology 102:603-609. 
707 Machinet, G. E., I. Bertrand, Y. Barrière, B. Chabbert, and S. Recous. 2011. Impact of plant cell 708 wall network on biodegradation in soil: Role of lignin composition and phenolic acids in 709 roots from 16 maize genotypes. Soil Biology and Biochemistry 43:1544-1552.

710 Makkonen, M., M. P. Berg, I. T. Handa, S. Hättenschwiler, J. Ruijven, P. M. Bodegom, and R. 711 Aerts. 2012. Highly consistent effects of plant litter identity and functional traits on 712 decomposition across a latitudinal gradient. Ecology letters 15:1033-1041.

713 Meentemeyer, V. 1978. Macroclimate and lignin control of litter decomposition rates. Ecology 714 59:465-472.

715 Milcu, A., and P. Manning. (2011) All size classes of soil fauna and litter quality control the 716 acceleration of litter decay in its home environment. Oikos 120:1366-1370.

717 Monties, B. 1984. Dosage de la lignine insoluble en milieu acide: influence du prétraitement par 718 hydrolyse acide sur la lignine klason de bois et paille. Agronomie 4:387-392.

719 Moorhead, D., G. Lashermes, S. Recous, and I. Bertrand. 2014. Interacting microbe and litter 720 quality controls on litter decomposition: a modeling analysis. Plos One 9: e108769. doi:10.1371/journal.pone.0108769.

722 Moorhead, D. L., and R. L. Sinsabaugh. 2006. A theoretical model of litter decay and microbial 723 interaction. Ecological Monographs 76:151-174.

724 Pearse, I. S., R. C. Cobb, and R. Karban. 2014. The phenology-substrate-match hypothesis 725 726 explains decomposition rates of evergreen and deciduous oak leaves. Journal of Ecology

727 Perez, G., M. Aubert, T. Decaens, J. Trap, and M. Chauvat. (2013) Home-Field Advantage: A 728 matter of interaction between litter biochemistry and decomposer biota. Soil Biology and $729 \quad$ Biochemistry 67:245-254. 
730 Powers, J. S., R. A. Montgomery, E. C. Adair, F. Q. Brearley, S. J. DeWalt, C. T. Castanho, J.

731 Chave, E. Deinert, J. U. Ganzhorn, and M. E. Gilbert. 2009. Decomposition in tropical

732 forests: a pan-tropical study of the effects of litter type, litter placement and mesofaunal

733 exclusion across a precipitation gradient. Journal of Ecology 97:801-811.

734 Purahong, W., M. Schloter, M. J. Pecyna, D. Kapturska, V. Däumlich, S. Mital, F. Buscot, M.

735 Hofrichter, J. L. Gutknecht, and D. Krüger. 2014. Uncoupling of microbial community

736 structure and function in decomposing litter across beech forest ecosystems in Central

$737 \quad$ Europe. Scientific reports 4.

738 Sinsabaugh, R., M. Carreiro, and D. Repert. 2002. Allocation of extracellular enzymatic activity

739 in relation to litter composition, $\mathrm{N}$ deposition, and mass loss. Biogeochemistry 60:1-24.

740 Strickland, M. S., E. Osburn, C. Lauber, N. Fierer, and M. A. Bradford. 2009a. Litter quality is

741 in the eye of the beholder: initial decomposition rates as a function of inoculum

742 characteristics. Functional Ecology 23:627-636.

743 Strickland, M. S., E. Osburn, C. Lauber, N. Fierer, and M. A. Bradford. 2009b. Litter quality is

744 in the eye of the beholder: initial decomposition rates as a function of inoculum

$745 \quad$ characteristics. Functional Ecology 23:627-636.

746 Strickland, M. S., and J. Rousk. 2010. Considering fungal: bacterial dominance in soils-methods,

747 controls, and ecosystem implications. Soil Biology and Biochemistry 42:1385-1395.

748 Talbot, J. M., T. D. Bruns, J. W. Taylor, D. P. Smith, S. Branco, S. I. Glassman, S. Erlandson, R.

749 Vilgalys, H. L. Liao, and M. E. Smith. 2014. Endemism and functional convergence

750 across the North American soil mycobiome. Proceedings of the National Academy of

$751 \quad$ Sciences 111:6341-6346. 
752 Treseder, K. K., T. C. Balser, M. A. Bradford, E. L. Brodie, E. A. Dubinsky, V. T. Eviner, K. S.

753 Hofmockel, J. T. Lennon, U. Y. Levine, and B. J. MacGregor. 2012. Integrating

754 microbial ecology into ecosystem models: challenges and priorities. Biogeochemistry

755 109:7-18.

756 Trofymow, J., T. Moore, B. Titus, C. Prescott, I. Morrison, M. Siltanen, S. Smith, J. Fyles, R.

757 Wein, and C. Camiré. 2002. Rates of litter decomposition over 6 years in Canadian

758 forests: influence of litter quality and climate. Canadian Journal of Forest Research

$759 \quad 32: 789-804$.

760 Van Der Heijden, M. G., R. D. Bardgett, and N. M. Van Straalen. 2008. The unseen majority:

761 soil microbes as drivers of plant diversity and productivity in terrestrial ecosystems.

$762 \quad$ Ecology letters 11:296-310.

763 Veen, G. F., G. T. Freschet, A. Ordonez, and D. A. Wardle. 2015. Litter quality and

764 environmental controls of home-field advantage effects on litter decomposition. Oikos

$765 \quad 124: 187-195$.

766 Veen, G. F., M. K. Sundqvist, and D. A. Wardle. 2015. Environmental factors and traits that

767 drive plant litter decomposition do not determine home-field advantage effects.

$768 \quad$ Functional Ecology 29:981-991.

769 Vivanco, L., and A. T. Austin. 2008. Tree species identity alters forest litter decomposition

770 through long-term plant and soil interactions in Patagonia, Argentina. Journal of Ecology

$77196: 727-736$.

772 Wall, D. H., M. A. Bradford, J. ST, J. A. Trofymow, V. BEHAN-PELLETIER, D. E. Bignell, J.

773 Dangerfield, W. J. Parton, J. Rusek, and W. Voigt. 2008. Global decomposition 

Change Biology 14:2661-2677.

776 Wallenstein, M. D., M. L. Haddix, E. Ayres, H. Steltzer, K. A. Magrini-Bair, and E. A. Paul. 2013. Litter chemistry changes more rapidly when decomposed at home but converges during decomposition-transformation. Soil Biology and Biochemistry 57:311-319.

779 Wallenstein, M. D., A. M. Hess, M. R. Lewis, H. Steltzer, and E. Ayres. 2010. Decomposition of 780 aspen leaf litter results in unique metabolomes when decomposed under different tree

781 species. Soil Biology and Biochemistry 42:484-490.

782 Wickings, K., A. S. Grandy, S. C. Reed, and C. C. Cleveland. 2012. The origin of litter chemical 783 complexity during decomposition. Ecology letters 15:1180-1188.

\section{4}

\section{Ecological Archives}

786 Appendices A-I are available online: 


\section{Tables}

789 Table 1. ANOVA results with the percentage sums of squares explained (\%SS) for the effects of 790 soil, litter type and their interactions on the cumulative carbon mineralisation. Raw data or net

791 data (corrected by control soils) were used.

\begin{tabular}{|c|c|c|c|c|c|c|c|}
\hline \multirow{2}{*}{ Source of variation } & \multirow{2}{*}{ df } & \multicolumn{3}{|c|}{ Raw data } & \multicolumn{3}{|c|}{ Net data } \\
\hline & & $\% \mathrm{SS}$ & $\mathrm{F}$ & P-value & $\% \mathrm{SS}$ & $\mathrm{F}$ & P-value \\
\hline \multicolumn{8}{|l|}{27 days } \\
\hline Soil type & 3 & 9.6 & 114.3 & $<0.0001$ & 1.9 & 21.2 & $<0.0001$ \\
\hline Litter type & 3 & 89.3 & 1066.6 & $<0.0001$ & 96.8 & 1066.6 & $<0.0001$ \\
\hline Soil type $\times$ Litter type & 9 & 0.3 & 1.0 & $0.45^{\mathrm{NS}}$ & 0.3 & 1.0 & $0.45^{\mathrm{NS}}$ \\
\hline Error & 32 & 0.9 & & & 1.0 & & \\
\hline \multicolumn{8}{|l|}{97 days } \\
\hline Soil type & 3 & 22.9 & 430.3 & $<0.0001$ & 2.4 & 35.0 & $<0.0001$ \\
\hline Litter type & 3 & 76.1 & 1431.7 & $<0.0001$ & 96.4 & 1431.7 & $<0.0001$ \\
\hline Soil type $\times$ Litter type & 9 & 0.4 & 2.6 & 0.024 & 0.5 & 2.6 & 0.024 \\
\hline Error & 32 & 0.6 & & & 0.7 & & \\
\hline \multicolumn{8}{|l|}{202 days } \\
\hline Soil type & 3 & 32.1 & 791.0 & $<0.0001$ & 4.0 & 69.0 & $<0.0001$ \\
\hline Litter type & 3 & 66.9 & 1647.8 & $<0.0001$ & 94.7 & 1647.8 & $<0.0001$ \\
\hline Soil type $\times$ Litter type & 9 & 0.5 & 4.2 & 0.0011 & 0.7 & 4.2 & 0.0011 \\
\hline Error & 32 & 0.4 & & & 0.6 & & \\
\hline
\end{tabular}

792 Note: Significant differences are displayed in boldface. 
793 Table 2. Results of linear mixed models to test for the effects of soil type and time on the net 794 carbon mineralisation rates.

\begin{tabular}{|c|c|c|c|c|c|c|c|}
\hline \multirow{2}{*}{ Litter type } & \multirow{2}{*}{ Incubation period } & \multicolumn{3}{|c|}{ Soil type } & \multicolumn{3}{|c|}{ Soil type $\mathrm{x}$ Time } \\
\hline & & df & $\mathrm{F}$ & $P$-value & $\mathrm{df}$ & $\mathrm{F}$ & P-value \\
\hline \multirow{3}{*}{ Cropland } & 0 - 27 days & 3,8 & 10.76 & 0.0035 & 18,48 & 21.11 & $<0.0001$ \\
\hline & 28 - 97 days & 3,8 & 8.83 & 0.0064 & 18,48 & 5.30 & $<0.0001$ \\
\hline & 98 - 202 days & 3,8 & 37.60 & $<0.0001$ & 18,48 & 0.96 & $0.52^{\mathrm{NS}}$ \\
\hline \multirow{3}{*}{ Forest } & 0 - 27 days & 3,8 & 13.10 & 0.0019 & 18,48 & 11.38 & $<0.0001$ \\
\hline & 28 - 97 days & 3,8 & 20.42 & $<0.0001$ & 18,48 & 6.14 & $<0.0001$ \\
\hline & 98 - 202 days & 3,8 & 10.75 & 0.0035 & 18,48 & NS & $0.40^{\mathrm{NS}}$ \\
\hline \multirow{3}{*}{ Grassland } & 0 - 27 days & 3,8 & 2.96 & $0.10^{\mathrm{NS}}$ & 18,48 & 8.12 & $<0.0001$ \\
\hline & 28 - 97 days & 3,8 & 34.69 & $<0.0001$ & 18,48 & 1.50 & $0.13^{\mathrm{NS}}$ \\
\hline & 98 - 202 days & 3,8 & 2.69 & $0.12^{\mathrm{NS}}$ & 18,48 & 10.62 & $<0.0001$ \\
\hline \multirow{3}{*}{ Plantation } & 0 - 27 days & 3,8 & 6.48 & 0.016 & 18,48 & 14.27 & $<0.0001$ \\
\hline & 28 - 97 days & 3,8 & 13.57 & 0.0017 & 18,48 & 10.74 & $<0.0001$ \\
\hline & 98 - 202 days & 3,8 & 147.99 & $<0.0001$ & 18,48 & 1.77 & $0.06^{\mathrm{NS}}$ \\
\hline
\end{tabular}

795 Note: Results were analysed based on litter types and incubation periods. Significant differences

796 are displayed in boldface. 
797 Table 3. PERMANOVA evaluating the effects of soil type, litter type and time on (A) the

798 microbial community structure and (B) enzymatic activities.

\begin{tabular}{|c|c|c|c|c|c|c|}
\hline A Microbial community structure & df & SS & MS & F.model & P-value & $r^{2}$ \\
\hline Soil type & 3 & 0.14 & 0.05 & 71.6 & $<0.0001$ & 0.36 \\
\hline Litter type & 3 & 0.07 & 0.02 & 36.8 & $<0.0001$ & 0.18 \\
\hline Time & 2 & 0.05 & 0.24 & 36.9 & $<0.0001$ & 0.12 \\
\hline Litter type $\times$ Time & 6 & 0.04 & 0.01 & 9.2 & $<0.0001$ & 0.09 \\
\hline Soil type $\times$ Time & 6 & 0.02 & 0.00 & 4.1 & $<0.0001$ & 0.04 \\
\hline Soil type $\times$ Litter type & 9 & 0.00 & 0.00 & 0.7 & $0.94^{\mathrm{NS}}$ & 0.01 \\
\hline Residuals & 114 & 0.07 & 0.00 & & & 0.19 \\
\hline Total & 143 & 0.39 & & & & \\
\hline B Enzymes & df & SS & MS & F.model & $P$-value & $r^{2}$ \\
\hline Soil type & 3 & 0.11 & 0.037 & 66.3 & $<0.0001$ & 0.28 \\
\hline Litter type & 3 & 0.02 & 0.005 & 9.4 & $<0.0001$ & 0.04 \\
\hline Time & 2 & 0.10 & 0.050 & 88.5 & $<0.0001$ & 0.25 \\
\hline Litter type $\times$ Time & 6 & 0.01 & 0.001 & 2.7 & 0.012 & 0.02 \\
\hline Soil type $\times$ Time & 6 & 0.08 & 0.013 & 22.6 & $<0.0001$ & 0.19 \\
\hline Soil type $\times$ Litter type & 9 & 0.02 & 0.002 & 4.2 & $<0.0001$ & 0.05 \\
\hline Residuals & 114 & 0.06 & 0.001 & & & 0.16 \\
\hline Total & 143 & 0.40 & & & & \\
\hline
\end{tabular}

799 Note: Permutational multivariate ANOVA were performed to examine the relative influences of

800 soil type, litter type, time, and the interactions between these three explanatory variables on the

801 variation in the microbial community PLFA-based structure and enzymatic activities over the

802 course of the incubation experiment. 


\section{Figures}

804 Fig. 1. Schematic diagrams of the interactions between litter quality and soil microbial

805 communities during decomposition as expected when considering (A) the initial litter quality

806 (LQ) hypothesis: carbon mineralisation throughout decomposition is a function of initial litter

807 quality, with the most labile litters showing the highest carbon mineralisation rates in all

808 environments; (B) the functional breadth hypothesis (FB): decomposer communities from

809 recalcitrant ecosystems have a wider functional ability to decompose a wide range of chemical

810 compounds, with all litter types showing the highest carbon mineralisation rates in

811 poor/recalcitrant litter environments; and (C) the home-field advantage (HFA) hypothesis:

812 decomposer communities are locally adapted to their own litter, with each litter type

813 decomposing fastest in an area dominated by the plant species from which it was derived than in

814 an area dominated by another plant species. Based on the degree of recalcitrance of plant cell

815 walls that varied strongly between Gramineae and woody plant species, and on the nitrogen

816 content that was almost threefold higher in the grassland litter compared with the cropland litter,

817 we defined the relative ranking of litter quality as following: F. arundinacea, T. aestivum, $R$.

818 pseudoacacia and F. sylvatica. The + sign indicates that the carbon mineralisation rate is higher

819 for the plant-soil interactions, which are illustrated by arrows in the different panels. All + signs

820 represent patterns of variation rather than absolute values.

821

822 Fig. 2. Raw cumulative carbon mineralisation obtained for each (A) litter type and (B) soil type.

823 Each point represents a mean across all types of soils or among the different litters under

824 decomposition at a given time. Priming effect obtained after the addition of ${ }^{13} \mathrm{C}$ labelled flax 
825 litter was represented for each ecosystem type (C). A negative priming effect indicates that SOM

826 mineralisation is higher in the control than in the residue-amended treatment.

827

828 Fig. 3. Non-metric multidimensional scaling (NMDS) ordination based on Bray-Curtis distances

829 of (A) microbial community composition (stress $=0.22)$ and $(B)$ enzymes (stress $=0.06)$.

830 Different symbols represent the different types of soil: cropland (grey circles), forest (black

831 squares), grassland (white triangles), and plantation (dark grey diamonds). The lines correspond

832 to the distance between the calculated centroid and the projection of the different samples per

833 soil. The ellipses represent the average projection area of the samples from the centroid of each

834 soil.

835

836 Fig. 4. Parameter estimates of the net cumulative carbon mineralisation calculated using the new

837 approach developed by Keiser et al. (2014) for (A) LQ, (B) FB, and (C) HFA. LQ relates to the

838 relative ability of each different litter to be mineralized by all the decomposer communities used

839 in our experiment. FB quantifies the overall functional ability of each decomposer community.

840 HFA estimates the interaction between the litter decomposition and the decomposer communities

841 in each ecosystem.

842

843 Fig. 5. Correlations between the parameter estimates of sugar mass loss as a function of the net 844 integrated enzymatic activity, which was calculated using the model presented in Fig. 4. The

845 parameter estimates represent the expected parietal sugar mass loss or enzymatic synthesis for 846 either FB (white symbols) or HFA (grey symbols): cropland (circles), forest (squares), grassland

847 (triangles), and plantation (diamonds). The parietal sugar mass loss is the mean of all of the 848 monosaccharides in the cell wall: L-arabinose, D-glucose, D-xylose, D-galactose, L-rhamnose, 
849 D-mannose, L-fucose, D-galacturonic acid and D-glucuronic acid. The net integrated enzymatic 850 activity is the mean of all of the carbon-related enzymes $(\beta-1,4$-glucosidase, $\beta$-D-cellobiosidase,

851 a-glucosidase, and $\beta$-xylosidase) after correction by the 'no-litter treatment' soil.
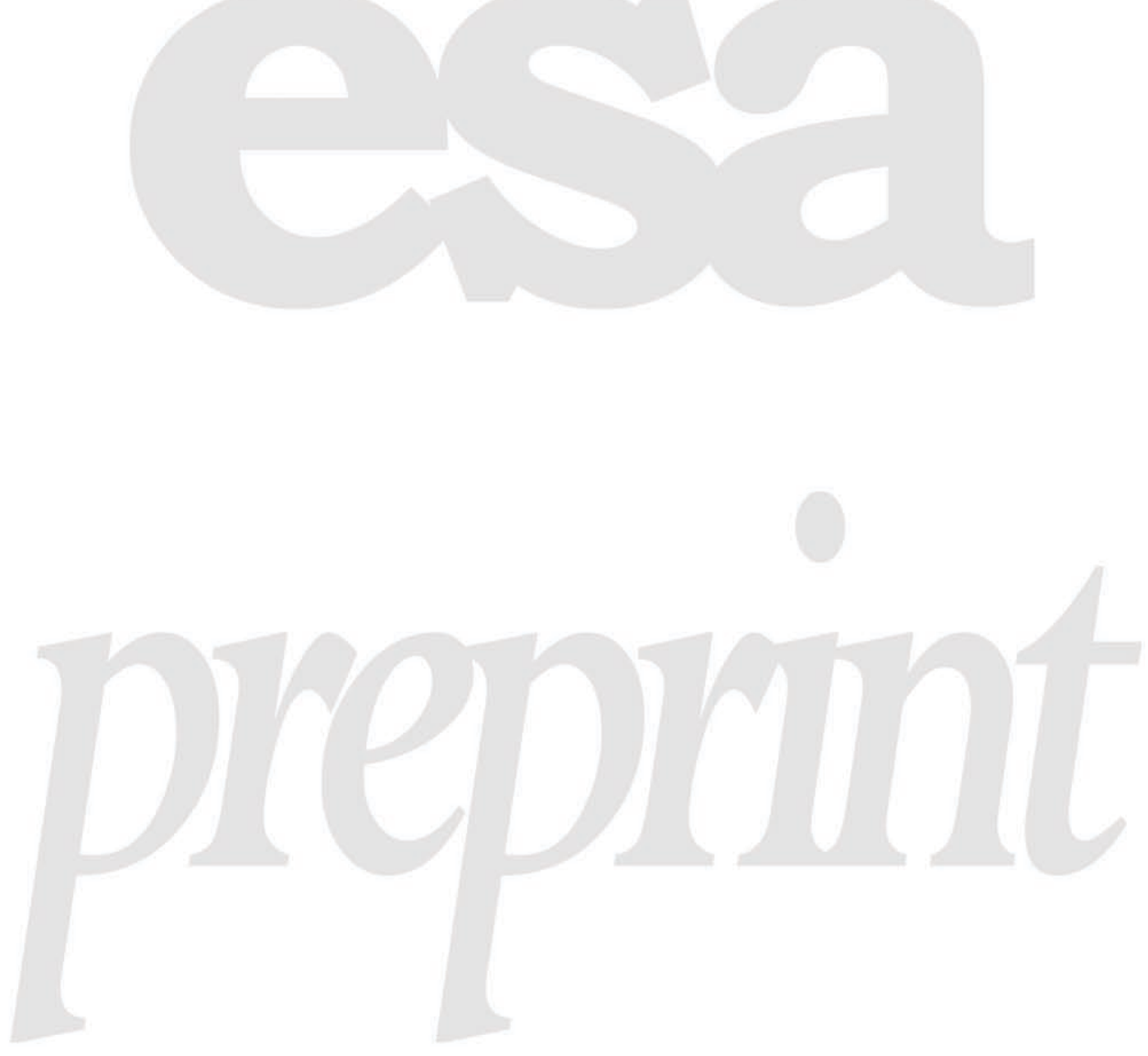


\section{Figure 1.}

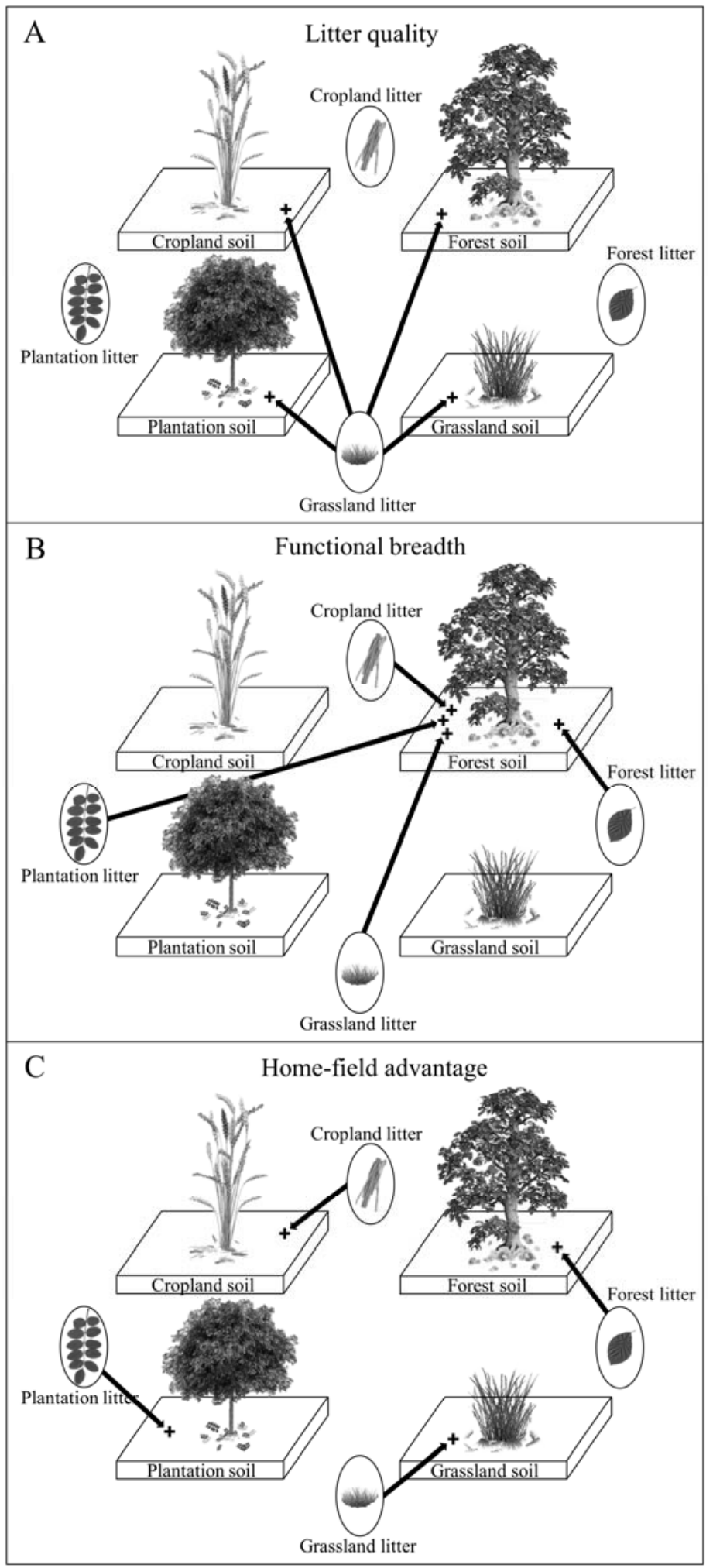


853 Figure 2.
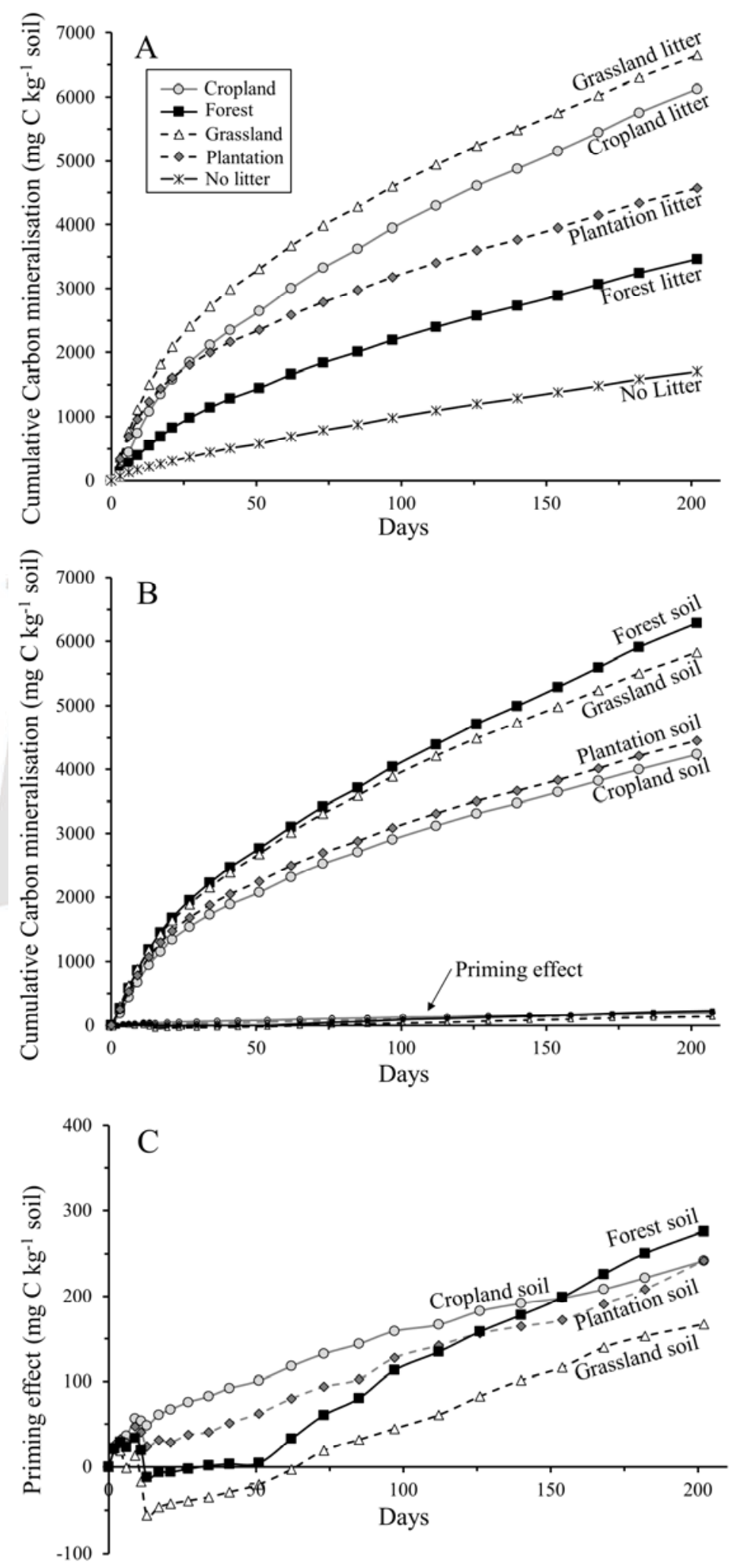


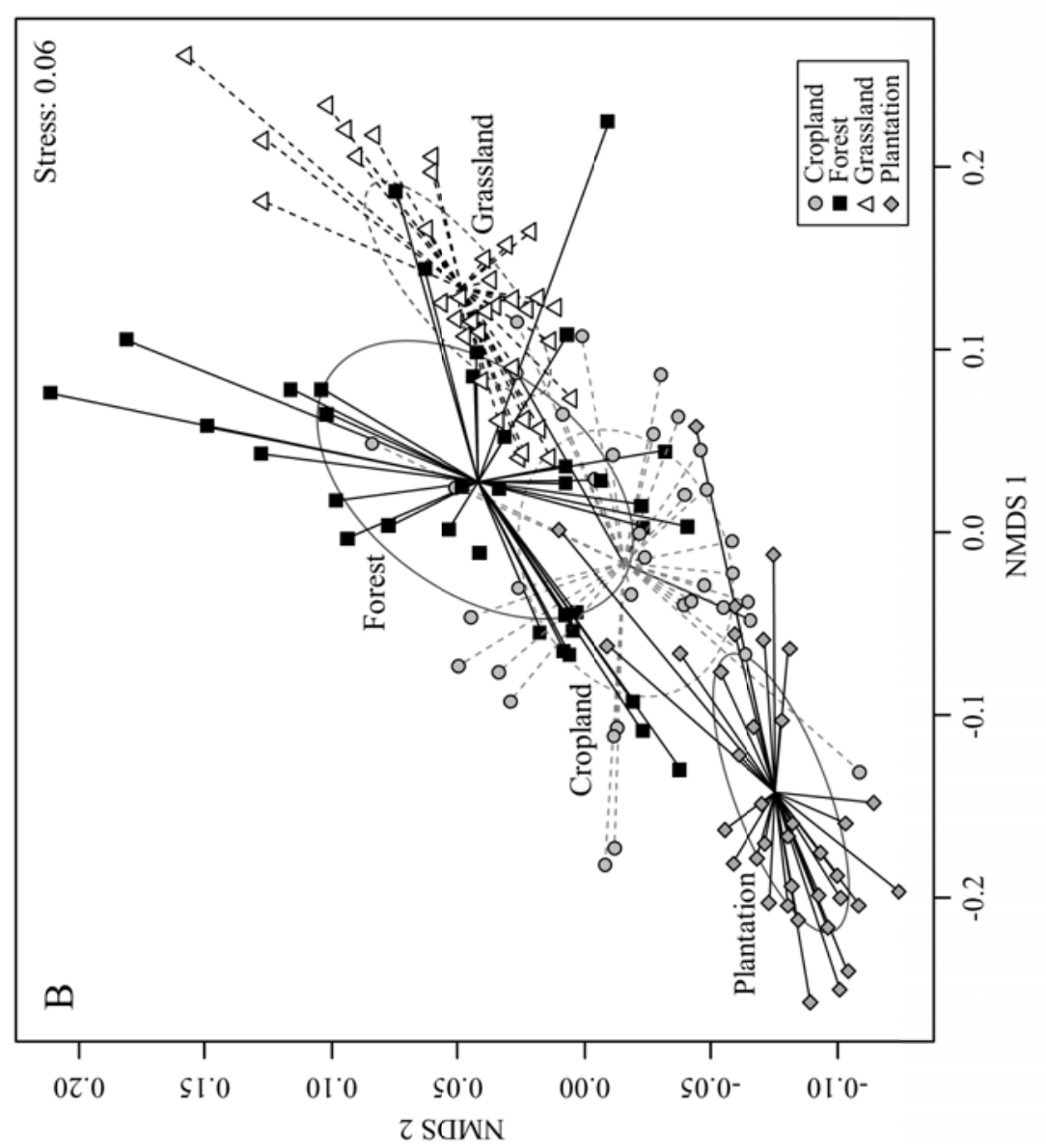

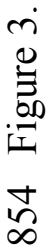

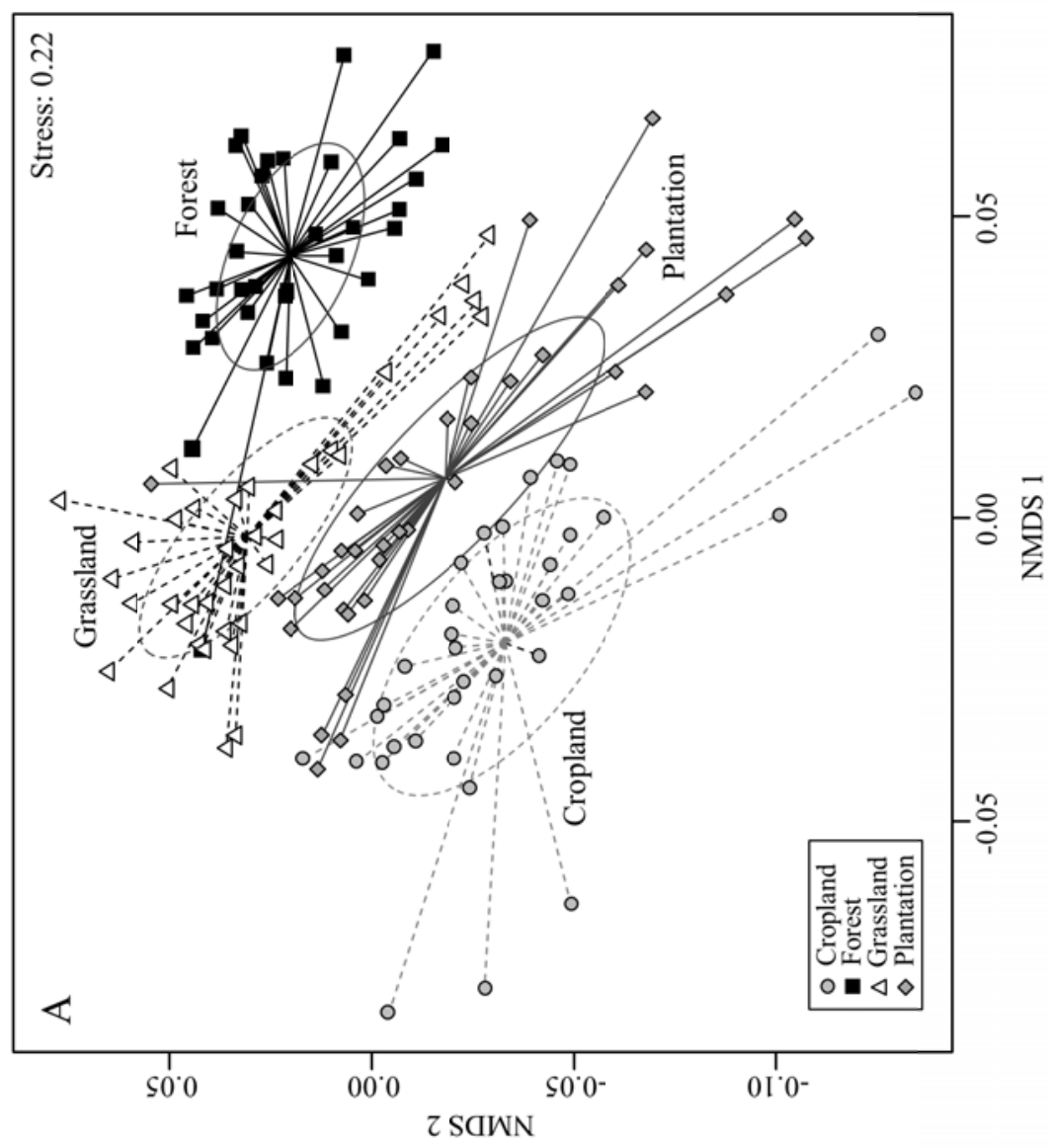


855 Figure 4.
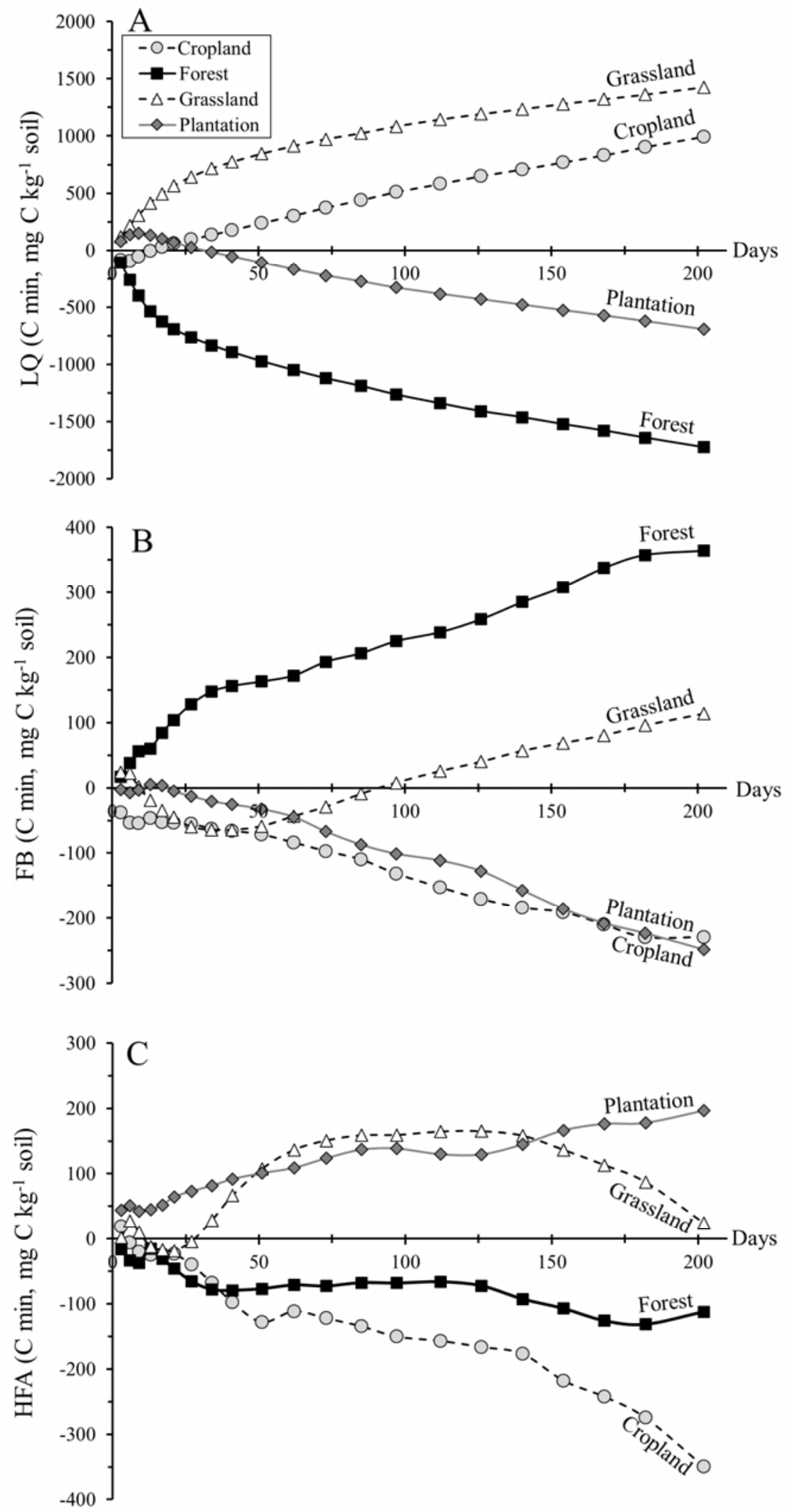
856 Figure 5.

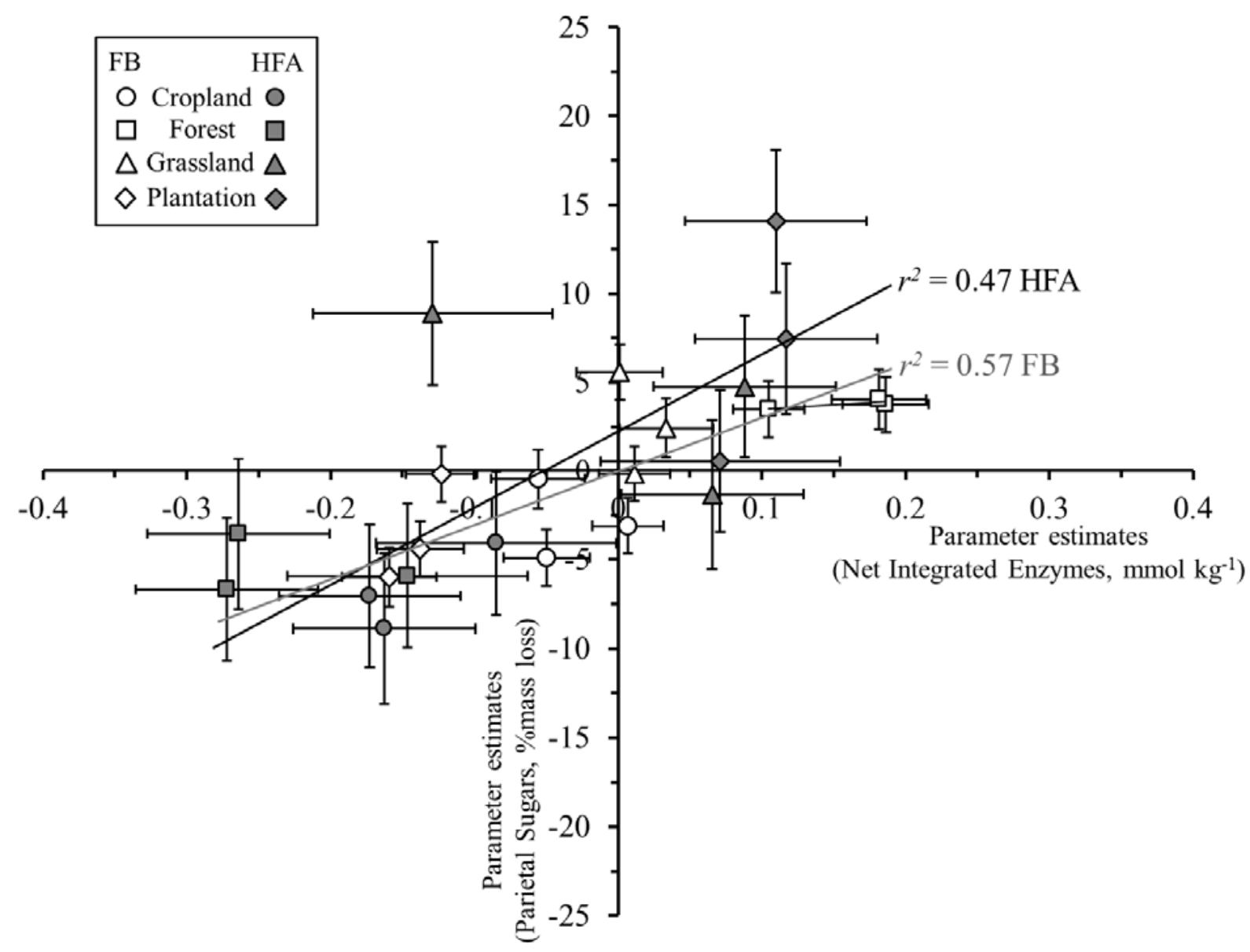

